FEDERAL RESERVE BANK OF SAN FRANCISCO

WORKING PAPER SERIES

\title{
Monetary Policy and Real Exchange Rate Dynamics in Sticky-Price Models
}

\author{
Carlos Carvalho \\ Central Bank of Brazil \\ PUC Rio \\ Fernanda Nechio
}

Federal Reserve Bank of San Francisco

Fang Yao

RB New Zealand

September 2018

Working Paper 2014-17

http://www.frbsf.org/economic-research/publications/working-papers/2014/17/

\section{Suggested citation:}

Carvalho, Carlos, Fernanda Nechio, Fang Yao. 2019. "Monetary Policy and Real Exchange Rate Dynamics in Sticky-Price Models,” Federal Reserve Bank of San Francisco Working Paper 2014-17. http://www.frbsf.org/economic-

research/publications/working-papers/wp2014-17.pdf

The views in this paper are solely the responsibility of the authors and should not be interpreted as reflecting the views of the Federal Reserve Bank of San Francisco or the Board of Governors of the Federal Reserve System. 


\title{
Monetary Policy and Real Exchange Rate Dynamics in Sticky-Price Models*
}

\author{
Carlos Carvalho \\ Central Bank of Brazil \\ PUC-Rio
}

Fernanda Nechio

FRB San Francisco

April 7, 2019

\author{
Fang Yao \\ RB New Zealand
}

\begin{abstract}
We study how real exchange rate dynamics are affected by monetary policy in dynamic, stochastic, general equilibrium, sticky-price models. Our analytical and quantitative results show that the source of interest rate persistence - policy inertia or persistent policy shocks - is key. In the presence of persistent monetary shocks, increasing policy inertia may decrease real exchange rate persistence, hampering the ability of sticky-price models to generate persistent real exchange rate deviations from parity.
\end{abstract}

JEL classification codes: F3, F41, E0

Keywords: real exchange rates, monetary policy, interest rate smoothing, PPP puzzle, persistence.

*For comments and suggestions we thank seminar participants at the Workshop of the Australasian Macroeconomics Society 2016, Econometric Society Australasian Meetings 2016, Macquarie University Sydney, Reserve Bank of Australia, Reserve Bank of New Zealand, University of Otago, UT at Austin, European Economic Association 2014, and the San Francisco Fed. The views expressed in this paper are those of the authors and do not necessarily reflect the position of the Central Bank of Brazil, the Federal Reserve Bank of San Francisco, the Federal Reserve System, or the Reserve Bank of New Zealand. E-mails: cvianac@econ.puc-rio.br, fernanda.nechio@sf.frb.org, fang.yao@rbnz.govt.nz. 


\section{Introduction}

The open economy macroeconomics literature has struggled to develop models that can replicate the empirical evidence of high persistence and volatility of real exchange rate (RER) fluctuations in response to shocks - in particular, to monetary shocks. This difficulty came to be known as the Purchasing Power Parity (PPP) puzzle, as put forth by Rogoff (1996). Within this literature, Engel (2012) and Benigno (2004) highlight the interaction between monetary policy and price stickiness. In a standard one-sector sticky-price model, they find that price stickiness only matters for real exchange rate persistence when monetary policy features policy inertia. ${ }^{1}$ In that context, if the degree of policy inertia is strong enough (i.e., the smoothing component of the interest rate rule followed by the monetary authority is large), the model can generate some persistence in the dynamic response of the real exchange rate to monetary policy shocks that are serially uncorrelated.

The empirical macroeconomics literature, however, shows an ongoing debate about the source of interest rate persistence observed in the data. For example, Rudebusch (2002) provides evidence that it arises mainly from persistent monetary shocks, whereas Coibion and Gorodnichenko (2012) point to policy inertia as the main source of interest rate persistence. Both papers provide some evidence that monetary policy rules likely feature both sources of persistence.

In this paper we study the extent to which the modeling choice for the source interest rate persistence matters for real exchange rate dynamics in sticky-price DSGE models. To do so, we study versions of the two-country multisector model of Carvalho and Nechio (2011) with different specifications of the monetary policy rule. That model produces empirically plausible real exchange rate dynamics in response to nominal aggregate demand disturbances. We drop the assumption of an exogenous nominal aggregate demand process in favor of explicit monetary policy rules. In particular, we use a standard Taylor (1993) rule, and allow for persistent policy shocks and/or policy inertia (interest rate smoothing) as possible sources of interest rate persistence. Whereas the model of Carvalho and Nechio (2011) features heterogeneity in the degree of price stickiness across sectors, to relate our findings to Engel (2012) and Benigno (2004), we also entertain one-sector versions of the model, in which the degree of price rigidity is the same for all firms.

We find that the source of interest rate persistence — policy inertia or persistent policy

\footnotetext{
${ }^{1}$ Benigno (2004) studies a one-sector model in which he allows the frequency of price changes for exporting goods to differ from the frequency for domestic price setting. He also allows for an asymmetry in the frequency of price changes across countries. He shows that when this heterogeneity leads to different frequencies of price changes within a same country (due to differences in frequencies for varieties produced by local versus foreign firms), the real exchange rate becomes more persistent.
} 
shocks - matters a great deal. Quantitatively, persistent policy shocks go a long way in generating real exchange rate persistence. When the model features heterogeneity in frequency of price adjustment, a calibration that matches the U.S. distribution of price stickiness is able to match the empirical properties of the RER impulse response function. In contrast, policy inertia leads the model to produce low levels of real exchange rate persistence. In fact, if the policy rule followed by the monetary authorities has too strong an interest rate smoothing component, even the multisector sticky-price model fails to generate meaningful real exchange rate persistence in response to monetary shocks.

Note that, while our finding that policy inertia hampers the ability of the model to generate RER persistence may seem to contradict the results in Engel (2012) and Benigno (2004), this is not the case. Consistent with those papers, in response to i.i.d. policy shocks, we find that real exchange rate persistence is increasing in the degree of policy inertia. Likewise, absent policy inertia, RER persistence increases with the degree of (positive) autocorrelation of monetary shocks. These results hold for both multisector and one-sector versions of our model.

When both policy inertia and persistent monetary shocks are present, however, the comparative statics results become richer. If the degree of (positive) serial autocorrelation of monetary shocks is not too high, RER persistence continues to increase with the degree of policy inertia. Hence, the findings of Engel (2012) and Benigno (2004) extend to the case of not-too-persistent monetary policy shocks. However, this ceases to be true when monetary shocks are persistent enough. In that case, introducing policy inertia decreases RER persistence. We show these results analytically in a simplified one-sector model, and confirm that they continue to hold in our calibrated multisector and one-sector economies.

Intuitively, the source of interest rate persistence affects the endogenous response of the main model variables and, therefore, it affects the persistence of the real exchange rate response to monetary shocks. This holds in both one-sector and multisector economies. In a multisector economy, the dynamics of the real exchange rate also depend on the distribution of price stickiness. Analytically, in a two-sector economy, we show that the dynamics of the real exchange rate depend on relative sectoral prices. In this two-sector economy, relative sectoral prices determine the ability of the multisector economy to yield a hump-shaped impulse response functions, which is key to matching the empirical evidence of persistent deviations of RER from parity in response to monetary shocks (Cheung and Lai, 2000, Steinsson, 2008, and Iversen and Söderström, 2014).

Although we focus our analysis on open economy models, our lessons are not limited to this context. As highlighted by Engel (2012), the lessons apply to some closed-economy models that are isomorphic to their open-economy versions. Moreover, lessons from open-economy models 
such as the ones we analyze are likely to hold approximately in their closed-economy versions whenever the degree of home bias in consumption is large enough. In those cases, the effects of different monetary policy rules should show up in the dynamics of real variables such as consumption and output. Overall, our results on the different effects of alternative choices for the source of interest rate persistence in the model highlight the importance of the empirical debate on this issue (e.g. Rudebusch, 2002, and Coibion and Gorodnichenko, 2012).

Finally, besides the connection with Benigno (2004) and Engel (2012), our paper is related more broadly to the literature that uses dynamic sticky-price models to study the persistence of real exchange rates, such as, among others, Bergin and Feenstra (2001), Kollmann (2001), Chari, Kehoe and McGrattan (2002), Steinsson (2008), Johri and Lahiri (2008), Martínez-García and Søndergaard (2013), and Iversen and Söderström (2014).

In Section 2 we present the model, details of the calibration, and a quantitative analysis of the effects of different monetary policy rules on RER dynamics. Section 3 derives analytical results for a simplified version of the model, which show that RER persistence may decrease in the presence of policy inertia. We follow with a discussion of the mechanisms behind our findings. The last section concludes.

\section{The model}

Rogoff (1996) detailed the challenges faced by the theoretical literature in trying to match features of the response of RERs to monetary shocks. In particular, standard (one-sector) New Keynesian models have a hard time replicating the large persistence (and volatility) of real exchange rates in response to monetary shocks. Within this literature, Engel (2012) and Benigno (2004) use a standard (one-sector) New Keynesian model and show that the interaction between monetary policy and price stickiness matters for the dynamics of the real exchange rate when monetary policy features policy inertia. Engel (2012) and Benigno (2004)'s results, however, corroborate those of Rogoff (1996) in that they also find that the model-implied real exchange rate persistence (in response to monetary shock) falls short of matching the empirical evidence.

Carvalho and Nechio (2011), on the other hand, argue that a multisector two-country New Keynesian economy (calibrated to match the U.S. distribution of price stickiness) goes a long way toward replicating the dynamic features of the RER response monetary shocks. The authors, however, focus on a model that leaves the monetary policy rule implicit by setting an exogenous specification for nominal demand.

In what follows, we bridge the gap between the contributions of Engel (2012), Benigno 
(2004) and Carvalho and Nechio (2011) by departing from the latter multisector model while considering, instead, alternative specifications for the policy rule. We then use the quantitative analysis as a guideline for the subsequent discussion about how the source of monetary persistence matters in these models.

For brevity, we provide some key ingredients of the multisector model of Carvalho and Nechio (2011). We depart from their model by introducing an explicit monetary policy rule in place of an exogenous specification for nominal demand. For additional details on the model, we refer the reader to their paper.

The world economy consists of two symmetric countries, Home and Foreign. In each country, identical consumers supply labor to intermediate firms that they own, invest in a complete set of state-contingent financial claims, and consume a nontraded final good. The latter goods are produced by competitive firms that combine intermediate varieties produced in the two countries. In turn, these varieties are produced by monopolistically competitive firms that are divided into sectors that differ in their frequency of price changes, which is the only (ex-ante) source of heterogeneity in the model. Intermediate firms can price-discriminate across countries and set prices in local currency.

The Home representative consumer chooses consumption of the final good, $C_{t}$, and total labor supply $N_{t}$, to maximize:

$$
E_{0} \sum_{t=0}^{\infty} \beta^{t}\left(\frac{C_{t}^{1-\sigma}-1}{1-\sigma}-\frac{N_{t}^{1+\gamma}}{1+\gamma}\right)
$$

subject to the flow budget constraint:

$$
P_{t} C_{t}+E_{t}\left[\Theta_{t, t+1} B_{t+1}\right] \leq W_{t} N_{t}+B_{t}+T_{t}
$$

and a standard "no-Ponzi" condition. $\Theta_{t, l} \equiv \prod_{l^{\prime}=t+1}^{l} \Theta_{l^{\prime}-1, l^{\prime}}, E_{t}$ denotes the time- $t$ expectations operator, $W_{t}$ is the corresponding nominal wage rate, and $T_{t}$ stands for net transfers from the government plus profits from Home intermediate firms. The final good sells at the nominal price $P_{t}$, and $B_{t+1}$ accounts for the state-contingent value of the portfolio of financial securities held by the consumer at the beginning of $t+1$. Under complete financial markets, agents can choose the value of $B_{t+1}$ for each possible state of the world at all times. A no-arbitrage condition requires the existence of a nominal stochastic discount factor $\Theta_{t, t+1}$ that prices, in period $t$, any financial asset portfolio with state-contingent payoff $B_{t+1}$ at the beginning of period $t+1$. $^{2}$ Finally, $\beta$ is the time-discount factor, $\sigma^{-1}$ denotes the intertemporal elasticity of substitution,

\footnotetext{
${ }^{2}$ To avoid cluttering the notation, we omit explicit reference to the different states of nature.
} 
and $\gamma^{-1}$ is the Frisch elasticity of labor supply.

The Foreign consumer solves an analogous problem and maximizes:

$$
\begin{array}{cc} 
& E_{0} \sum_{t=0}^{\infty} \beta^{t}\left(\frac{C_{t}^{* 1-\sigma}-1}{1-\sigma}-\frac{N_{t}^{* 1+\gamma}}{1+\gamma}\right), \\
\text { s.t. } \quad & P_{t}^{*} C_{t}^{*}+E_{t}\left[\Theta_{t, t+1}^{*} \frac{B_{t+1}^{*}}{\mathcal{E}_{t}}\right] \leq W_{t}^{*} N_{t}^{*}+\frac{B_{t}^{*}}{\mathcal{E}_{t}}+T_{t}^{*},
\end{array}
$$

and a "no-Ponzi" condition. A superscript "*" denotes the Foreign counterpart of the corresponding Home variable. Without loss of generality, we assume that the complete set of state-contingent assets are denominated in the Home currency. As a result, in the budget constraint above, $B_{t}^{*}$ appears divided by the nominal exchange rate, $\mathcal{E}_{t}$, to convert the value of the portfolio into Foreign currency. $\mathcal{E}_{t}$ is defined as the price of the Foreign currency in terms of the Home currency, hence, it is quoted in units of Home currency per unit of the Foreign currency. Under complete markets and free trade of assets there are no arbitrage opportunities, and hence, the stochastic discount factor has to be the same for both countries.

Defining $Q_{t} \equiv \mathcal{E}_{t} \frac{P_{t}^{*}}{P_{t}}$ as the real exchange rate, and assuming $Q_{0} \frac{C_{0}^{-\sigma}}{C_{0}^{*-\sigma}}=1$, from Home and Foreign Euler equations one obtains:

$$
Q_{t}=\frac{C_{t}^{*-\sigma}}{C_{t}^{-\sigma}} .
$$

A representative competitive firm produces the final good, which is a composite of varieties of intermediate goods from both countries. Monopolistically competitive firms produce each variety. The latter firms are divided into sectors indexed by $s \in\{1, \ldots, S\}$, each featuring a continuum of firms. Sectors differ in the degree of price rigidity, as we detail below. Overall, firms are indexed by the country where they produce, by their sector, and are further indexed by $j \in[0,1]$. The distribution of firms across sectors is given by sectoral weights $f_{s}>0$, with $\sum_{s=1}^{S} f_{s}=1$.

The final good combines the intermediate varieties according to the technology:

$$
\begin{aligned}
Y_{t} & =\left(\sum_{s=1}^{S} f_{s}^{\frac{1}{\eta}} Y_{s, t}^{\frac{\eta-1}{\eta}}\right)^{\frac{\eta}{\eta-1}} \\
Y_{s, t} & =\left(\omega^{\frac{1}{\rho}} Y_{H, s, t}^{\frac{\rho-1}{\rho}}+(1-\omega)^{\frac{1}{\rho}} Y_{F, s, t}^{\frac{\rho-1}{\rho}}\right)^{\frac{\rho}{\rho-1}} \\
Y_{H, s, t} & =\left(f_{s}^{\frac{\theta-1}{\theta}} \int_{0}^{1} Y_{H, s, j, t}^{\frac{\theta-1}{\theta}} d j\right)^{\frac{\theta}{\theta-1}} \\
Y_{F, s, t} & =\left(f_{s}^{\frac{\theta-1}{\theta}} \int_{0}^{1} Y_{F, s, j, t}^{\frac{\theta-1}{\theta}} d j\right)^{\frac{\theta}{\theta-1}}
\end{aligned}
$$


where $Y_{t}$ is the Home final good, $Y_{s, t}$ is the aggregation of sector- $s$ Home and Foreign intermediate goods sold in Home, $Y_{H, s, t}$ and $Y_{F, s, t}$ are the composites of intermediate varieties produced by firms in sector $s$ in Home and Foreign, respectively, to be sold in Home, and $Y_{H, s, j, t}$ and $Y_{F, s, j, t}$ are the varieties produced by firm $j$ in sector $s$ in Home and Foreign to be sold in Home. The parameters $\eta \geq 0, \rho \geq 0$, and $\theta>1$ are, respectively, the elasticity of substitution across sectors, the elasticity of substitution between Home and Foreign goods, and the elasticity of substitution within sectors. Finally, $\omega \in[0,1]$ is the steady-state share of domestic inputs.

A representative Home final-good-producing firm solves:

$$
\begin{array}{ll}
\max & P_{t} Y_{t}-\sum_{s=1}^{S} f_{s} \int_{0}^{1}\left(P_{H, s, j, t} Y_{H, s, j, t}+P_{F, s, j, t} Y_{F, s, j, t}\right) d j \\
\text { s.t. } & (2)-(5),
\end{array}
$$

where $P_{H, s, j, t}$ is the price charged in the Home market by Home firm $j$ from sector $s$, and $P_{F, s, j, t}$ is the price charged in the Home market by Foreign firm $j$ from sector $s$. Both $P_{H, s, j, t}$ and $P_{F, s, j, t}$ are set in the Home currency.

Monopolistically competitive firms produce varieties of the intermediate good by employing labor. As in Carvalho and Nechio (2011), these firms set prices as in Calvo (1983). The frequency of price changes varies across sectors, and in each period, each firm $j$ in sector $s$ changes its price independently with probability $\alpha_{s}$. This is the only source of (ex-ante) heterogeneity.

At each time a Home-firm $j$ from sector $s$ adjusts its price, it chooses prices $X_{H, s, j, t}, X_{H, s, j, t}^{*}$ to be charged in the Home and Foreign markets, respectively, with each price being set in the corresponding local currency. The maximization problem is:

$$
\begin{aligned}
& \quad \max E_{t} \sum_{l=0}^{\infty} \Theta_{t, t+l}\left(1-\alpha_{s}\right)^{l}\left[X_{H, s, j, t} Y_{H, s, j, t+l}+\mathcal{E}_{t+l} X_{H, s, j, t}^{*} Y_{H, s, j, t+l}^{*}-W_{t+l} N_{s, j, t+l}\right] \\
& \text { s.t. } Y_{H, s, j, t}+Y_{H, s, j, t}^{*}=N_{s, j, t}^{\chi} \text {, and demand for intermediate inputs, }
\end{aligned}
$$

where $\chi$ determines returns to labor.

Finally, the market clearing conditions for Home include $N_{t}=\sum_{s=1}^{S} f_{s} \int_{0}^{1} N_{s, j, t} d j$, and likewise for Foreign.

Note that when all sectors have the same frequency of price adjustment, the multisector economy becomes a standard one-sector sticky-price model. In our quantitative analysis, we consider a one-sector economy with frequency of price changes equal to the average frequency of adjustments in the multisector economy, i.e., $\bar{\alpha}=\sum_{s=1}^{S} f_{s} \alpha_{s}$. 


\subsection{Monetary policy}

To close the model we specify a monetary policy rule. We consider a Taylor-type interest rate rule of the form:

$$
\begin{aligned}
I_{t} & =\beta^{-1}\left(I_{t-1}\right)^{\rho_{i}}\left(\frac{P_{t}}{P_{t-1}}\right)^{\left(1-\rho_{i}\right) \phi_{\pi}}\left(\frac{G D P_{t}}{G D P}\right)^{\left(1-\rho_{i}\right) \phi_{Y}} e^{v_{t}} \\
v_{t} & =\rho_{v} v_{t-1}+\sigma_{\varepsilon_{v}} \varepsilon_{v, t},
\end{aligned}
$$

where $I_{t}$ is the nominal interest rate on one-period riskless bonds at time $t, G D P_{t} \equiv Y_{t}+$

$\sum_{s=1}^{S} f(s) \int_{0}^{1} Y_{H, s, j, t}^{*} d j-\sum_{s=1}^{S} f(s) \int_{0}^{1} Y_{F, s, j, t} d j$ is gross domestic product, ${ }^{3} G D P$ denotes gross domestic product in steady state, $\rho_{i}, \phi_{\pi}$, and $\phi_{Y}$ are the parameters associated with the interest rate rule, $v_{t}$ is a shock with persistence $\rho_{v} \in[0,1)$, and $\varepsilon_{v, t}$ is a zero mean, unit variance $i . i . d$. shock. We assume throughout that monetary policy in Foreign follows an analogous rule as in Home, and that monetary shocks are uncorrelated across the two countries.

We solve the model by log-linearizing around a zero-inflation steady state. For more details about the model and solution, we refer the reader to Carvalho and Nechio (2011).

\subsection{Quantitative results}

To parameterize the model, we follow Carvalho and Nechio (2011) (and the literature therein) and set $\sigma^{-1}$ to $1 / 3$, the (Frisch) labor supply elasticity $(\gamma)$ to unit, labor share $\chi$ to $2 / 3$, and the consumer's time preference rate to $2 \%$ per year. The elasticity of substitution between varieties within sectors is set to $\theta=10$, the elasticity of substitution between Home and Foreign goods is set to $\rho=1.5$, the elasticity of substitution between varieties of different sectors is set to unit $(\eta=1),{ }^{4}$ and the share of domestic goods is set to $\omega=0.9 .^{5}$

The parameterization approximates the U.S. empirical distribution of price stickiness reported by Nakamura and Steinsson (2008). In particular, departing from the 67-category distribution of price stickiness used in Carvalho and Nechio (2011), we use the methodology described in Carvalho and Nechio (2017) to construct a three-sector distribution that allows us to bypass the large computational cost of working with such large-scale models. More importantly, this approximation is such that the dynamic properties of aggregate variables in the multisector economies calibrated using the original and the three-sector approximate price distributions are extremely similar. Carvalho and Nechio (2017)'s approximation entails choosing frequencies of price changes and sectoral weights in the three-sector model to match moments of the

\footnotetext{
${ }^{3}$ The definition of GDP follows Chari, Kehoe and McGrattan (2002).

${ }^{4}$ Following Hobijn and Nechio (2017).

${ }^{5}$ Carvalho and Nechio (2011) provide more details on the choices for these parameter values.
} 
cross-sectional distribution of price stickiness of the original 67-sector economy. This method yields a three-sector distribution that, as the original one, features prices changing, on average, once every 4.7 months, the cross-sectional average of duration of price spells at 13.6 months, the cross-sectional standard deviation of durations at 11.7 months, the cross-sectional skewness of durations at 1.3 months, and the cross-sectional kurtosis of durations at 5.2 months. ${ }^{6}$

Turning to the specifications for monetary policy, we set $\phi_{\pi}=1.5, \phi_{Y}=0.5 / 12$, which are standard values for Taylor rules. We consider cases with persistent shocks only $\left(\rho_{v}>0\right.$, $\left.\rho_{i}=0\right)$, policy inertia only $\left(\rho_{v}=0, \rho_{i}>0\right)$, and with both persistent shocks and policy inertia $\left(\rho_{v}, \rho_{i}>0\right)$. We use the model with no policy inertia as a reference point, and calibrate $\rho_{v}$ to generate plausible RER dynamics. In particular, we choose $\rho_{v}$ to closely match the empirical half-life of deviations of RER from parity, in addition to roughly matching more nuanced features of the underlying empirical impulse response function. More specifically, we choose $\rho_{v}$ to match empirical moments of the real exchange rate as reported in Steinsson (2008). These moments are reported in the first column of Table 1 . This calibration yields $\rho_{v}=0.975$, which corresponds to roughly 0.9 at a quarterly frequency. Given this value, the other two cases featuring interest rate smoothing are meant to illustrate the effects of policy inertia. In Section 3 we extend the comparative statics and consider different parameterizations for $\rho_{i}$ and $\rho_{v}$.

Table 1: RER moments under alternative monetary policy specifications

\begin{tabular}{|c|c|c|c|c|c|c|c|}
\hline \multirow[b]{2}{*}{$\begin{array}{l}\text { Persistence } \\
\text { measures: }\end{array}$} & \multirow{2}{*}{$\begin{array}{l}\text { Data } \\
\\
(1) \\
\end{array}$} & \multicolumn{3}{|c|}{ Multisector economy } & \multicolumn{3}{|c|}{ One-sector economy } \\
\hline & & $\begin{array}{c}\rho_{v}=.975 \\
\rho_{i}=0 \\
\quad(2)\end{array}$ & $\begin{array}{c}\rho_{v}=0 \\
\rho_{i}=.975 \\
\quad(3)\end{array}$ & $\begin{array}{c}\rho_{v}=.975 \\
\rho_{i}=.975 \\
(4)\end{array}$ & $\begin{array}{c}\rho_{v}=.975 \\
\rho_{i}=0 \\
(5)\end{array}$ & $\begin{array}{c}\rho_{v}=0 \\
\rho_{i}=.975 \\
\quad(6)\end{array}$ & $\begin{array}{c}\rho_{v}=.975 \\
\rho_{i}=.975 \\
(7)\end{array}$ \\
\hline $\mathcal{H} \mathcal{L}$ & 54 & 53 & 6 & 8 & 28 & 4 & 4 \\
\hline $\mathcal{Q L}$ & 76 & 83 & 17 & 29 & 55 & 8 & 8 \\
\hline $\mathcal{U L}$ & 28 & 22 & 0 & 0 & 0 & 0 & 0 \\
\hline $\mathcal{C I R}$ & 80 & 71 & 14 & 24 & 40 & 6 & 7 \\
\hline$\rho_{1}$ & 0.8 & 0.9 & 0.7 & 0.7 & 0.8 & 0.6 & 0.6 \\
\hline
\end{tabular}

Note: The column labeled as "Data" shows the statistics obtained Steinsson (2008). The remaining columns report model-based statistics for different assumptions for monetary shock persistence and policy inertia.

Table 1 reports the results for different versions of the model. In terms of persistence, it shows results for the half-life $(\mathcal{H L})$ of RER deviations from parity, the quarter-life $(\mathcal{Q L})$, the up-life $(\mathcal{U L})$ of those deviations, and the cumulative impulse response $(\mathcal{C I} \mathcal{R})$. Results for all four measures are reported in months. The quarter-lives and the up-lives are meant

\footnotetext{
${ }^{6}$ Expenditure weights are $f_{1}=0.3815, f_{2}=0.4588, f_{3}=0.1598$, and the Calvo parameters are $\alpha_{1}=0.4524$, $\alpha_{2}=0.0725, \alpha_{3}=0.0338$.
} 
to provide a better picture of the shape of the impulse response function. They correspond to, respectively, the time it takes for the impulse response function to drop below $1 / 4$ of the initial impulse, and the time it takes for the real exchange rate to peak after the initial response. Hence, a hump-shaped impulse response function yields a nonzero up-life $(\mathcal{U L})$. The cumulative impulse response $(\mathcal{C I} \mathcal{R})$ measures the area under the impulse response function. Table 1 also includes the first-order autocorrelation of the real exchange rate $\left(\rho_{1}\right)$, as an additional measure of persistence. ${ }^{7}$

The first column of Table 1 shows empirical measures of persistence taken from Steinsson (2008), obtained by fitting simple time-series processes to RER data. These estimates imply that RER deviations from parity are long-lasting — within the 3-5 year "consensus" (Rogoff, 1996) — and yield a hump-shaped impulse response function.

Columns (2), (3) and (4) present the results for the baseline multisector model for three monetary policy specifications, respectively; $(i)$ persistent shocks only $\left(\rho_{v}=0.975, \rho_{i}=0\right)$, (ii) policy inertia only $\left(\rho_{v}=0\right.$ and $\left.\rho_{i}=0.975\right)$, and $(i i i)$ both $\left(\rho_{v}=0.975\right.$ and $\left.\rho_{i}=0.975\right)$. Columns (5), (6) and (7) present report the results for one-sector economies.

The results for multisector and one-sector models in Table 1 echo the findings of Carvalho and Nechio (2011). Multisector models significantly increase real exchange rate persistence when compared to their one-sector counterparts. In addition, in the case of persistent shocks only, the calibration of the multisector model produces RER dynamics that resemble the data along various dimensions of the underlying impulse response functions (i.e., $\mathcal{H} \mathcal{L}, \mathcal{Q L}$, and $\mathcal{U L}$ ).

A comparison of the three versions of the multisector economies, however, shows that the ability of the multisector model to generate empirically plausible RER dynamics disappears when the policy rule features policy inertia, as evidenced by columns (3) and (4) of Table 1. Columns (5) to (7) of Table 1 show that the RER persistence in the one-sector versions of the model also drop dramatically in the presence of a high degree of policy inertia.

It is clear from these results that the source of interest rate persistence matters a great deal for the dynamics of the RER in DSGE models. In both the multisector and the one-sector economies, introducing policy inertia to a model that features persistent shocks reduces RER persistence. This is evidenced in Table 1 by comparing, for example, columns (2) and (4) in the multisector economy, as well as columns (5) and (7) in the one-sector economy.

\footnotetext{
${ }^{7}$ Following Chari, Kehoe and McGrattan (2002), the first-order autocorrelations are based on HodrickPrescott (HP) filtered model-generated and realized data. To obtain this measure using realized data, we average the real exchange rate and the real GDP over three-month periods to obtain a quarterly series, to which we apply an HP filter with bandwidth 1600. For the model generated series, we simulate 100 replications of each economy with 508 observations each. After dropping the first 100 observations (yielding a sample of 408 observations, as in the data column), we average each series over three-month periods to obtain a quarterly series, to which we apply the HP filter.
} 
An additional feature of the multisector model with no policy inertia is that it is able to produce empirically plausible real exchange rate persistence measures and roughly match other properties of the impulse response function. One-sector economies and versions of the multisector one in which the policy rule features interest rate smoothing fail to do so. Notice that up-life $(\mathcal{U L})$ is nonzero exclusively in the multisector model with persistent monetary shocks only (column (2)).

Hence, there are two main takeaways from this calibration exercise. First, in both one-sector and multisector models policy inertia can decrease RER persistence. Second, a multisector economy that features persistent enough shocks (and no policy inertia) is able to generate impulse response functions that replicate the empirical properties of the response of RER to monetary shocks; i.e., high persistence and a hump-shaped response. In the next section, we further analyze these two findings, one at a time.

Finally, we note that in this exercise we follow the literature and compare unconditional data moments with model-implied moments generated by monetary shocks only. Appendix A provides the alternative exercise in which we match empirical RER moments conditional on identified monetary policy shocks to model-implied moments. To that end, we assess the dynamic properties of the real exchange rate in response to identified monetary shocks by revisiting the structural vector autoregression model of Eichenbaum and Evans (1995). In particular, we extend their sample from 1990 to 2007 and estimate the response of the RER of various countries to identified shocks to the Federal Funds Rate. Conditional RER moments do differ from unconditional moments that the literature has focused on. The dynamic response of RERs to monetary policy shocks is even more persistent than its unconditional dynamics. However, the lessons from our analysis of the different versions of the model are unchanged, irrespective of whether we discipline the reference model using unconditional or conditional RER moments.

\section{The role of monetary policy}

Engel (2012) and Benigno (2004) find that real exchange rate persistence increases with the degree of policy inertia $\left(\rho_{i}\right)$. Table 1 , on the other hand, shows cases under which the inclusion of policy inertia decreases RER persistence. In this section we investigate this apparent discrepancy.

First, using calibrated models, we show that whether RER persistence increases or decreases with the degree of policy inertia depends on the level of shock persistence in both one-sector and in multisector models. Then, we use a simplified version of the one-sector model to show 
analytically that RER persistence may indeed decrease in the presence of policy inertia. Finally, we use a simplified two-sector economy to show how heterogeneity in price rigidity endows the model with the ability to yield a hump-shaped RER impulse response function, which is key to replicating the empirical properties of the response of the RER to monetary shocks.

\subsection{Comparative statics in calibrated models}

Varying policy inertia $\left(\rho_{i}\right)$ when monetary shocks are:

(a) i.i.d. $\quad\left(\rho_{v}=0\right)$

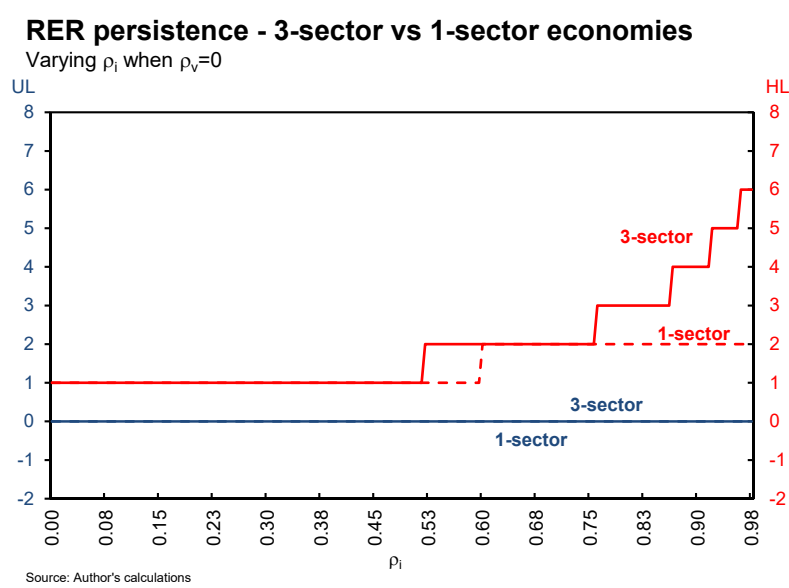

(b) persistent $\left(\rho_{v}>0\right)$

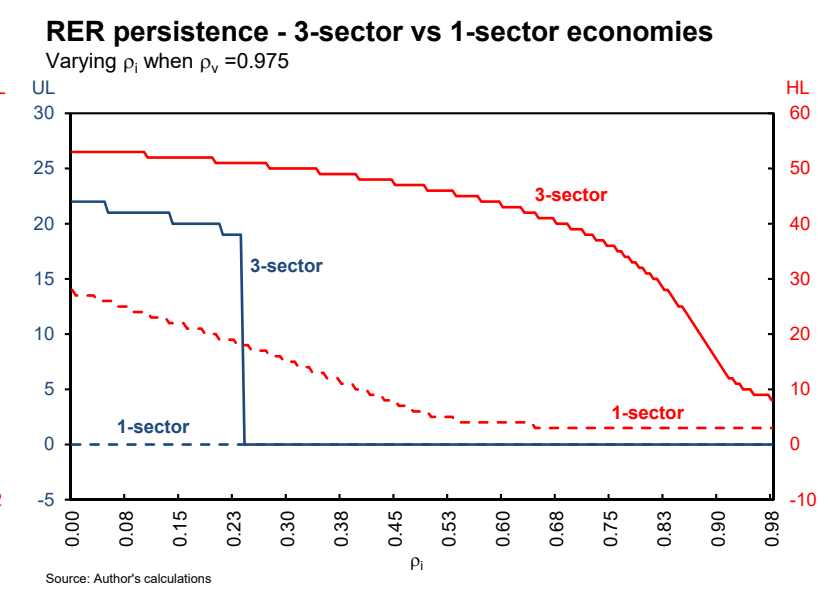

Figure 1: Up- and half-lives in response to monetary shocks for varying degrees of policy inertia

Figure 1 presents RER persistent measures for varying degrees of policy inertia $\left(\rho_{i}\right)$ and alternative specifications for shock persistence $\left(\rho_{v}\right)$ in calibrated models. ${ }^{8}$ Dashed lines indicate one-sector economies, whereas solid lines correspond to the three-sector models. The figure reports up-lives $(\mathcal{U L})$ and half-lives $(\mathcal{H} \mathcal{L})$. The left-hand-side panel assumes i.i.d. monetary policy shocks $\left(\rho_{v}=0\right)$, while the right-hand-side panel assumes a persistent monetary shock (in this example, with $\left.\rho_{v}=0.975\right)$. For brevity, other measures of persistence and other pairings of monetary policy parameters are reported in the Appendix Figures A2 and A3.

The left-hand-side panel shows that, in line with Engel (2012) and Benigno (2004), RER persistence increases with the degree of policy inertia $\left(\rho_{i}\right)$ when monetary shocks are serially uncorrelated. For i.i.d. monetary shocks, this pattern holds for both measures of persistence in both the multisector and the one-sector economies. ${ }^{9}$ The right-hand-side panel, however, shows

\footnotetext{
${ }^{8}$ All other parameters are held constant at values described in Section 2.2.

${ }^{9}$ Other measures of persistence show qualitatively similar results. See Appendix Figures A2 and A3.
} 
that results can change dramatically when monetary policy shocks are serially correlated. In this case, increasing the degree of policy inertia decreases RER persistence in both the multisector and the one-sector economies.

These panels also show that only the multisector model with a low degree of policy inertia is capable of generating nonzero up-lives (right panel). In other words, one-sector models fail to produce a hump-shaped impulse response function. As we discuss in Section 3.2, this is key to understanding the mechanism through which different monetary policy specifications affect RER dynamics in these models.

\subsection{Analytical results in a one-sector model}

In this section we make a set of simplifying assumptions to obtain some analytical results. In particular, we consider a one-sector economy with no home bias $(\omega=0.5)$, constant returns to labor $(\chi=1)$, and infinite Frisch elasticity of labor supply $(\gamma=0)$. These simplifications allow us to write the model with three equations for each country: a Phillips curve; an aggregate demand (derived from each countries' Euler equation); and an interest rate rule. As in Engel (2012), we can then solve the model by rewriting it in terms of deviations between Home and Foreign variables, where for any variable $x, d x_{t} \equiv x_{t}-x_{t}^{*}-i . e$, the difference between each variable's Home and Foreign counterparts. These simplifications yield:

$$
\begin{aligned}
d \pi_{t} & =\delta q_{t}+\beta E_{t} d \pi_{t+1} \\
\beta d i_{t} & =E_{t} q_{t+1}-q_{t}+E_{t} d \pi_{t+1}
\end{aligned}
$$

where $\delta=\frac{\bar{\alpha}(1-\beta(1-\bar{\alpha}))}{1-\bar{\alpha}}$ and $\bar{\alpha}=\sum_{s=1}^{S} f_{s} \alpha_{s}$ (as defined in Section 2). Equation (8) corresponds to the difference between Home and Foreign's Phillips curves. Equation (9) corresponds to the difference between Home and Foreign's Euler equations.

Assuming the same interest rate rule for both countries, equation (7) yields:

$$
d i_{t}=\rho_{i} d i_{t-1}+\left(1-\rho_{i}\right) \phi_{\pi} d \pi_{t}+v_{t}
$$

where $v_{t}$ follows an $\mathrm{AR}(1)$ process with parameter $\rho_{v} \in[0,1)$. Appendix B.1 provides details on the derivation of these three equations and the model solution.

Proposition 1 The solution to the simplified model (equations (8)-(10)) takes the form:

$$
\begin{aligned}
q_{t} & =\varphi_{q v} v_{t}+\gamma_{q} d i_{t-1} \\
d \pi_{t} & =\varphi_{\pi v} v_{t}+\gamma_{\pi} d i_{t-1},
\end{aligned}
$$


where $\varphi_{q v}, \varphi_{\pi v}, \gamma_{\pi}, \gamma_{q}$ are negative coefficients.

Corollary 1 Under the assumptions above, the cumulative impulse response function of the real exchange rate equals:

$$
\mathcal{C} \mathcal{I} \mathcal{R}(q)=\frac{1}{1-\rho_{v}}\left(1+\frac{\gamma_{q}}{\varphi_{q v}} \frac{\left(1+\left(1-\rho_{i}\right) \phi_{\pi} \varphi_{\pi v}\right)}{\left(1-\rho_{i}\right)\left(1-\phi_{\pi} \gamma_{\pi}\right)}\right)
$$

From Corollary 1, in the absence of policy inertia $\left(\rho_{i}=0\right), \gamma_{q}=\gamma_{\pi}=0$, and, hence, $\mathcal{C I R}(q)=\frac{1}{1-\rho_{v}}$. In this case, as in Engel (2012), persistence does not depend on price stickiness. When $\rho_{i}>0$, however, $\mathcal{C} \mathcal{I} \mathcal{R}(q)$ is given by equation (13), which is implicitly a function of price stickiness, as well as other parameters of the model.

From Proposition 1, $\gamma_{q} / \varphi_{q v}>0$, and $\left(1-\rho_{i}\right)\left(1-\phi_{\pi} \gamma_{\pi}\right)>0$. Hence, whether $\mathcal{C} \mathcal{I} \mathcal{R}(q) \gtrless$ $\frac{1}{1-\rho_{v}}$ hinges on whether $\left(1+\left(1-\rho_{i}\right) \phi_{\pi} \varphi_{\pi v}\right) \gtrless 0$. One can show that $\left(1+\left(1-\rho_{i}\right) \phi_{\pi} \varphi_{\pi v}\right)<0$ whenever monetary shock persistence $\left(\rho_{v}\right)$ satisfies $\rho_{v}>\frac{(1+\beta+\delta)-\sqrt{(1+\beta+\delta)^{2}-4 \beta}}{2 \beta}>0$. This result leads to the following corollary.

Corollary 2 For $\rho_{v}^{\text {crit }}=\frac{(1+\beta+\delta)-\sqrt{(1+\beta+\delta)^{2}-4 \beta}}{2 \beta}>0$, whenever $\rho_{v}>\rho_{v}^{\text {crit }}$ introducing policy inertia $\left(\rho_{i}>0\right)$ lowers $R E R$ persistence, as measured by $\mathcal{C I R}(q)$, relative to the case of persistent monetary policy shocks only.

For this simplified model and the remaining parameter values assumed in Section 2.2, Corollary 2 implies that policy inertia decreases RER persistence (as measured by $\mathcal{C} \mathcal{I} \mathcal{R}(q)$ ) as long as $\rho_{v}>0.5$ (at a quarterly frequency — roughly 0.79 at a monthly frequency). ${ }^{10}$ Hence, for standard parameter values and an empirically plausible degree of monetary shock persistence, policy inertia may decrease RER persistence.

Needless to say, the expression for $\rho_{v}^{\text {crit }}$ in Corollary $\mathbf{2}$ is only valid under the simplifying assumptions used in this section. Deviations from an economy with those characteristics will change the threshold for $\rho_{v}$, and can potentially make it a function of other parameters.

On a separate note, while in this paper we focus on the sources of interest rate persistence, in Appendix C.2 we also consider the interaction between technology shocks and policy inertia. More specifically, we entertain a small variant of the model in which we add a productivity shock $A_{t}$ to the production function described in equation (6) such that $Y_{H, s, j, t}+Y_{H, s, j, t}^{*}=A_{t} N_{s, j, t}^{\chi}, A_{t}$ evolves according to $\log A_{t}=\rho_{A} \log A_{t-1}+\sigma_{\varepsilon_{A}} \varepsilon_{A, t}$, and $\varepsilon_{A, t}$ is a unit variance i.i.d. shock. We show analytically that the cumulative impulse response function of the real exchange rate in

\footnotetext{
${ }^{10}$ Namely, one-sector economy, consumer time preference rate at $2 \%$ per year, no home bias $(\omega=0.5), \chi=1$, $\gamma=0, \phi_{y}=0, \phi_{\pi}=1.5$, and average frequency of price adjustment such that prices adjust on average every 4.7 months $(\bar{\alpha}=.22)$.
} 
the one-sector simplified model (as described in Section 3.2) unequivocally increases with policy inertia. Appendix Figure A4 shows that this finding also holds quantitatively when considering the fully-specified multisector and one-sector economies of Section 2.

Corollaries 1 and 2 show that as $\rho_{v}$ raises above the threshold $\rho_{v}^{\text {crit }},\left(1+\left(1-\rho_{i}\right) \phi_{\pi} \varphi_{\pi v}\right)$ turns negative. The latter term, which for simplicity we will refer to as $\tilde{\varphi}_{\pi v}$, ends up defining how interest rates responds to the monetary shock on impact.

To see why, note that, from the guessed solution, the policy rule can be rewritten as:

$$
d i_{t}=\left[\rho_{i}+\left(1-\rho_{i}\right) \phi_{\pi} \gamma_{\pi}\right] d i_{t-1}+\underbrace{\left[1+\left(1-\rho_{i}\right) \phi_{\pi} \varphi_{\pi v}\right]}_{\tilde{\varphi}_{\pi v} \gtrless 0} v_{t} .
$$

Therefore, the endogenous interest rate response on impact equals $\tilde{\varphi}_{\pi v}$. Corollary 2 implies that the response of $d i_{t}$ on impact has the same sign as $v_{1}$ as long as $\rho_{v}<\rho_{v}^{\text {crit }}$. For $\rho_{v}>\rho_{v}^{\text {crit }}$, the nominal rate (endogenously) increases on impact, in response to an expansionary shock $\left(v_{1}<0\right)$.

The increase in nominal interest rates in response to a persistent expansionary shock is not all that surprising. Galí (2015, Chapter 3) shows that in New Keynesian models with somewhat persistent monetary shocks, the endogenous response of prices to an expansionary monetary shock can be such that the nominal interest rate increases on impact. In that case, Proposition 1, along with Corollaries 1-2 adds to Galí (2015)'s findings by showing that introducing policy inertia reduces real exchange rate persistence. ${ }^{11}$

\subsection{Hump-shaped response to monetary shocks in a two-sector model}

The PPP Puzzle literature has highlighted the difficulties of standard New Keynesian models in replicating the empirical properties of the response of RER rates to monetary shocks. The results of the previous sections show that, under some conditions, adding policy inertia can further hamper the ability of the one-sector model to generate high levels of RER persistence.

The literature has also highlighted the importance of a model's ability to generate humpshaped impulse response functions in order to get close to the empirical features of the response of real exchange rates to monetary shocks. In particular, Cheung and Lai (2000) and Steinsson

\footnotetext{
${ }^{11}$ Appendix B.1.5 introduces a third corollary which shows how introducing policy inertia into a model with persistent shocks affects the speed of convergence of nominal interest rates and inflation. In particular, Corollary 3 shows that in this simplified one-sector economy, when $\rho_{v}>\rho_{v}^{\text {crit }}$, introducing policy inertia $\left(\rho_{i}>0\right)$ into to the model unequivocally increases the rate of convergence of $i_{t}$ back to steady state, while it reduces the convergence speed of $d \pi_{t}$. Since in these models the dynamics of the RER are tied by the Euler equation, these findings imply that for $\rho_{v}>\rho_{v}^{c r i t}$, the RER convergence speed back to its steady state increases, i.e., RER persistence declines.
} 
(2008) argue that the ability of a model to produce hump-shaped RER dynamics is key to matching the degree of persistence seen in the data. Going a step further in the analysis, Steinsson (2008) concludes that one-sector sticky-price models struggle to induce hump-shaped RER dynamics in response to monetary shocks.

Our results corroborate these findings. Indeed, as can be seen from Table 1, the only model that succeeds in producing enough RER persistence in response to monetary shocks is the one that is able to generate pronounced hump-shaped RER dynamics, i.e., the multisector economy with persistent monetary shocks (reported in column (2) of Table 1).

But how can the multisector model generate hump-shaped RER dynamics in response to monetary shocks? Let's revisit the simplified model of Section 3.2 while considering, instead, a two-sector economy. In particular, we maintain the same set of simplifying assumptions from that section but assume that each country has two equally-weighted sectors with different degrees of price rigidity.

As in the simplified one-sector economy, we can write this model in terms of deviations between Home and Foreign variables. This yields a set of four equations:

$$
\begin{aligned}
\beta d i_{t} & =E_{t} q_{t+1}-q_{t}+E_{t} d \pi_{t+1} \\
d \pi_{t} & =\beta E_{t} d \pi_{t+1}+f\left(\kappa_{1}+\kappa_{2}\right) q_{t}+f\left(\kappa_{2}-\kappa_{1}\right) d r p_{1, t} \\
d \pi_{1, t} & =\beta E_{t} d \pi_{1, t+1}+\kappa_{1} q_{t}-\kappa_{1} d r p_{1, t} \\
d r p_{1, t} & =d r p_{1, t-1}+d \pi_{1, t}-d \pi_{t}
\end{aligned}
$$

where $f=(1-f)$ is sector-1 weight, $\kappa_{j}=\frac{\alpha_{j}\left(1-\beta\left(1-\alpha_{j}\right)\right)}{1-\alpha_{j}}$, and $\alpha_{j}$ is the frequency of price adjustment in sector $j$, for $j=1,2$.

Equation (15) corresponds to the difference between Home and Foreign Euler equation, which is unchanged relative to the simplified one-sector model, equation (9). Equation (16) corresponds to the difference between Home and Foreign's Phillips curves. Relative to the onesector sector economy, it gains an additional term that depends on relative sectoral prices, i.e., $d r p_{1, t}=d p_{1, t}-d p_{t}$. Similarly, the model also includes a relationship between the difference between Home and Foreign's sectoral inflation, $d \pi_{1, t}$, and $d r p_{1, t}$, as described by equation (17). Appendix B.2 provides details on the model derivation. ${ }^{12}$

\footnotetext{
${ }^{12}$ Note that the Phillips curve in equation (16) nests the standard case in which there is only one sector in the model. In that case, $\kappa_{1}=\kappa_{2}$, and the relationship simplifies to equation (8).
} 
Proposition 2 The solution to the simplified two-sector model takes the form:

$$
\begin{aligned}
d \pi_{t} & =\varphi_{\pi} v_{t}+\gamma_{\pi} d i_{t-1}+\theta_{\pi} d r p_{1, t-1}, \\
q_{t} & =\varphi_{q} v_{t}+\gamma_{q} d i_{t-1}+\theta_{q} d r p_{1, t-1}, \\
d r p_{1, t} & =\varphi_{p} v_{t}+\gamma_{p} d i_{t-1}+\theta_{p} d r p_{1, t-1},
\end{aligned}
$$

where $\varphi_{\pi}, \varphi_{q}, \varphi_{p}, \gamma_{\pi}, \gamma_{q}, \gamma_{p}, \theta_{\pi}, \theta_{q}$, and $\theta_{p}$ are negative coefficients.

The model solution described in Proposition 2 differs from the one in Proposition 1 in that variables' dynamics depend not only on the shock and the (lagged) nominal interest rate, but also on $d r p_{1, t-1}$. The term $d r p_{1, t-1}$ explicitly identifies the channel through which heterogeneity in price stickiness affects the response of the real exchange rate.

To illustrate how relative sectoral prices affect the dynamics of real exchange rates in response to shocks, we consider versions of this model calibrated with different distributions of price stickiness. In particular, we parameterize stickiness in this simplified equally-weighted, two-sector, two-country model such that sector one is completely flexible, and sector two is such that firms adjusts prices, on average, once every (i) 6 months, and (ii) 24 months.

For each of these two cases, we parameterize the model for a range of shock persistence and policy inertia pairs. More specifically, for each case $(i)$ and (ii), we range shock persistence and policy inertia from 0 to 0.95 (in increments of 0.01) and obtain persistence measures from the resulting IRFs of $q_{t}$ and $d r p_{1, t-1}$. This exercise yields distributions of persistence measures under varying assumptions for $\rho_{v}$ and $\rho_{i}$, and for degrees of heterogeneity as in cases $(i)$ and (ii).

Based on this exercise, first, we compare the distribution of up-lives $(\mathcal{U L})$ obtained from the responses of $q_{t}$ and $d r p_{1, t}$ under cases $(i)$ and $(i i)$. Next, we compare the distributions of $\mathcal{U L}$ s and $\mathcal{H} \mathcal{L}$ s of $q_{t}$ (real exchange rate) under cases $(i)$ and $(i i)$.

The first comparison shows that the IRFs of $q_{t}$ and $d r p_{1, t-1}$ yield the same up-lives in nearly all cases, indicating that the hump-shaped response of the real exchange rate in these models is determined by the dynamics of relative sectoral prices. More precisely, in $99 \%$ of the cases the $\mathcal{U L}$ of $q_{t}$ and $d r p_{1, t-1}$ perfectly coincide. In the remaining cases they differ by one month.

Turning to the second comparison, Figure 2 depicts the distribution of up- and half-lives obtained from the real exchange rate IRFs for the alternative degrees for heterogeneity of cases (i) and (ii), and ranging $\rho_{v} \in[0, .95)$ and $\rho_{i} \in[0, .95)$. The picture shows that as we move from case $(i)$ to $(i i)$, i.e., as the heterogeneity across the two sectors increases, the distributions of RER up- and half-lives shift to the right, i.e., a higher degree of heterogeneity yields higher up- 
and half-lives. ${ }^{13}$

Figure 2: RER persistence for increasing heterogeneity in a two-sector model.

$$
\text { Up-life Half-live }
$$
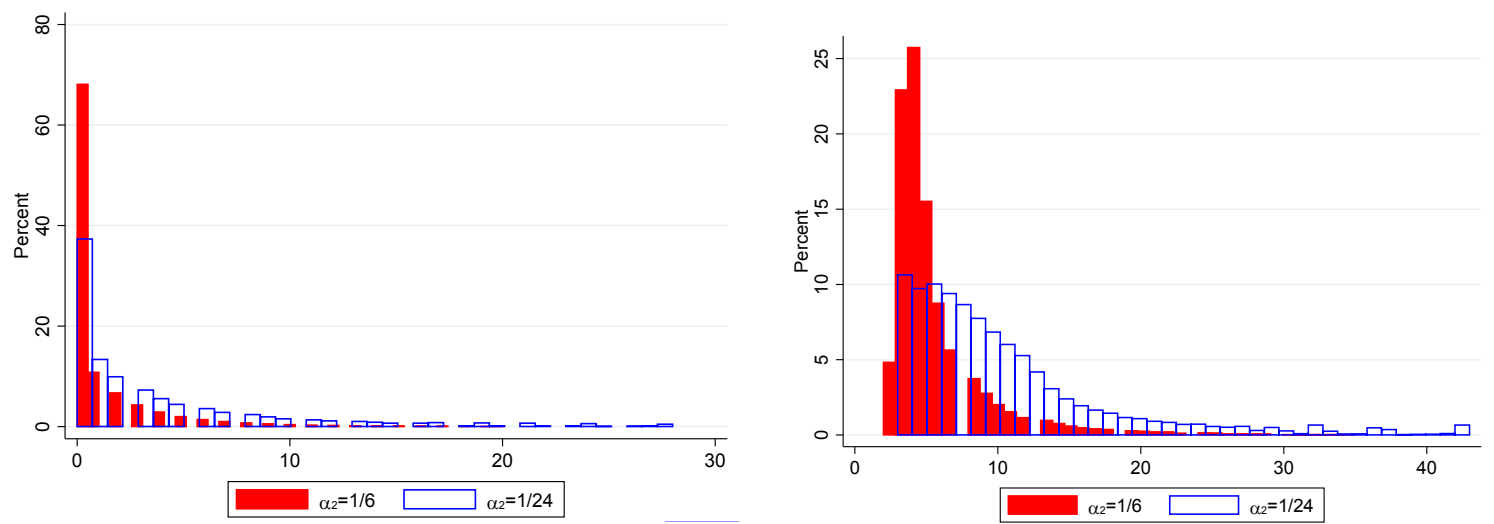

Note: Red bars show the histogram of real exchange rates up-lives for a two-sector simplified economy in which sector one is flexible and firms in sector 2 adjust prices, on average, once every 6 months. Blue bars report results when assuming that firms in sector 2 adjust prices, on average, once every 24 months. Shock persistence and policy inertia range from 0 to 0.95 (in increments of 0.01 ).

These findings highlight the role of heterogeneity in price stickiness in these models. The multisector economy yields a hump-shaped response that depends on the heterogeneity across sectors in the economy. Note that, while the introduction of a second sector can result in a hump-shaped response, the overall dynamics also depends on the shock persistence and policy inertia, which continue to play a role in the overall response of $q_{t}$ (as illustrated by equation (20)). Moreover, the patterns uncovered in Corollaries 1 and 2 remain valid. This can be seen in Figure 3 which reports the values attained by the up- and half-lives from the distributions of Figure 2 for different levels of shock persistence and policy inertia. In particular, the left-handside panel in Figure 3 reports mean up-lives obtained from the parameterizations $(i)$ and $(i i)$ for different values of $\rho_{v}$ and $\rho_{i}$. It shows that, despite heterogeneity, increasing policy inertia reduces the model's ability to generate positive up-lives. As a consequence, as policy inertia increases, the model also fails to produce large persistence, as illustrated in the right-hand-side panel of Figure 3 (half-lives decline as $\rho_{i}$ increases for both levels of heterogeneity).

\footnotetext{
${ }^{13}$ In unreported results, we considered adjusting sectoral weights such that the average frequency of price adjustment remained the same in cases $(i)$ and $(i i)$. In addition, we also considered versions in which firms in sector 2 adjust prices on average every other 12 and 36 months. The patterns illustrated in Figure 2 remain in all cases, i.e., as heterogeneity increases, the distribution of up-lives shifts rightwards. Results are available upon request.
} 
Figure 3: RER persistence for varying shock persistence and policy inertia in a two-sector model.
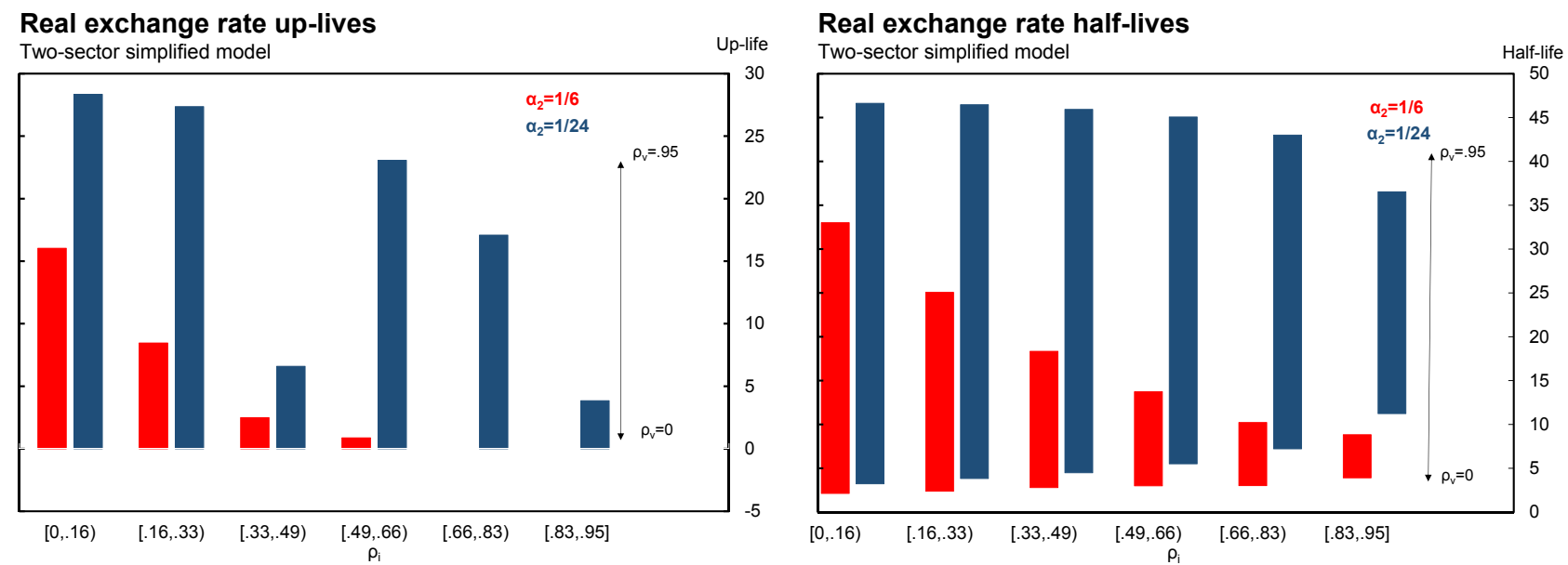

Note: Red bars show the range of real exchange rates up-lives (left-hand-side) and half-lives (right-hand-side) for a two-sector simplified economy in which sector one is flexible and firms in sector 2 adjust prices, on average, once every 6 months. Blue bars report results when assuming that firms in sector 2 adjust prices, on average, once every 24 months.

\section{Summary}

This section highlights two sets of findings regarding the dynamics of response of the real exchange to monetary shocks in sticky-price models.

The first finding pertains to the role of policy inertia for RER persistence in response to monetary shocks. We show that whether interest rate smoothing increases or decreases the persistence of RER in response to policy shocks hinges on the degree of persistence of the shock itself. Therefore, there is an interaction between endogenous and exogenous persistence. This result holds in a one-sector model (which we show analytically and numerically), and also in the multisector model (which we show numerically).

The second finding pertains to the hump-shaped response. As highlighted by Cheung and Lai (2000) and Steinsson (2008), a hump-shaped response of the RER is key to understanding its (high) persistence. Quantitatively, our results confirm their assessment by showing that the models that manage to produce high RER persistence in response to monetary shocks are precisely the ones that manage to produce a hump-shaped response, more specifically, the multisector models.

Results based on the simplified two-sector economy point to the channel through which the multisector dimension affects the dynamics of the RER. In particular, in the presence of heterogeneity in the frequency of price adjustment, the responses of the RER and other variables depend on relative sectoral prices. In calibrated versions of this two-sector economy, we find 
that the hump-shaped RER response follows the exact same dynamics of the relative sectoral price variable. The quantitative results also show that the more heterogeneous the two sectors are, the more pronounced the hump-shape (larger up-lives) and other persistence measures are. These results pin down the source of the hump-shaped dynamics in the multisector model, and at the same time show why the one-sector model fails in this dimension (since it does not feature this relative price component).

\section{Conclusion}

In this paper we study how different monetary policy rules affect RER dynamics in sticky-price models. We do so by entertaining a policy rule that allows for both persistent monetary shocks and policy inertia. We find that the source of interest rate persistence matters a great deal. When subjected to persistent monetary shocks, a multisector model with heterogeneous price stickiness can produce volatile and persistent RER. In particular, it can induce hump-shaped RER dynamics that resemble the patterns documented in the data.

Our results, however, show that when the monetary policy rule displays a strong enough degree of policy inertia, even the multisector sticky-price model fails to generate enough RER persistence in response to monetary shocks. In the presence of high shock persistence, policy inertia hampers the ability of the model to generate persistent deviations of real exchange rate from parity. Therefore, there is an interaction between endogenous and exogenous persistence.

Our findings also shed light on the relationship between the degree of heterogeneity and the ability of the models to generate a hump-shaped impulse response function, which is key to replicating the empirical properties of the real exchange rate in response to monetary shocks. In particular, in a simplified two-sector economy, we show that relative sectoral prices determine the (humped) shape of the real exchange rate response, and that the more heterogeneous the two sectors are, the more pronounced the hump-shape (larger up-lives) and other persistence measures are.

These results highlight the importance of the empirical debate on the source of the high degree of interest rate persistence observed in the data - whether it stems from persistent shocks, or from policy inertia (e.g., Rudebusch, 2002 and Coibion and Gorodnichenko, 2012).

\section{References}

Benigno, Gianluca. 2004. "Real exchange rate persistence and monetary policy rules." Journal of Monetary Economics, 51(3): 473-502. 
Bergin, Paul R., and Robert C. Feenstra. 2001. "Pricing-to-market, staggered contracts, and real exchange rate persistence." Journal of International Economics, 54(2): 333-359.

Calvo, Guillermo. 1983. "Staggered Prices in a Utility Maximizing Framework." Journal of Monetary Economics, 12: 383-398.

Carvalho, Carlos, and Fernanda Nechio. 2011. "Aggregation and the PPP Puzzle in a Sticky-Price Model." The American Economic Review, 101(6): pp. 2391-2424.

Carvalho, Carlos, and Fernanda Nechio. 2017. "Approximating New Keynesian Multisector Models." Federal Reserve Bank of San Francisco Working Paper Series 2017-12.

Chari, V. V, Patrick J. Kehoe, and Ellen R. McGrattan. 2002. "Can Sticky Price Models Generate Volatile and Persistent Real Exchange Rates?" Review of Economic Studies, $69(3): 533-563$.

Cheung, Yin-Wong, and Kon S Lai. 2000. "On the Purchasing Power Parity Puzzle." Journal of International Economics, 52(2): 321-330.

Coibion, Olivier, and Yuriy Gorodnichenko. 2012. "Why Are Target Interest Rate Changes so Persistent?" American Economic Journal: Macroeconomics, 4(4): 126-162.

Eichenbaum, Martin, and Charles L. Evans. 1995. "Some Empirical Evidence on the Effects of Shocks to Monetary Policy on Exchange Rates." The Quarterly Journal of Economics, 110(4): 975-1009.

Engel, Charles. 2012. "Real Exchange Rate Convergence: The Roles of Price Stickiness and Monetary Policy." Manuscript. Downloaded from http://www.ssc.wisc. edu/ cengel/WorkingPapers/Price $\% 20$ Stickiness $\% 20$ and $\% 20$ the $\% 20$ Real $\% 20$ Exchange $\%$ 20Rate11-27-12.pdf.

Galí, Jordi. 2015. Monetary Policy, Inflation, and the Business Cycle: An Introduction to the New Keynesian Framework and Its Applications Second edition. Economics Books, Princeton University Press.

Hobijn, Bart, and Fernanda Nechio. 2017. "Sticker shocks: using VAT changes to estimate upper-level elasticities of substitution." Federal Reserve Bank of San Francisco Working Paper Series 2015-17.

Iversen, Jens, and Ulf Söderström. 2014. "The Dynamic Behavior of the Real Exchange Rate in Sticky Price Models: Comment." American Economic Review, 104(3): 1072-89. 
Johri, Alok, and Amartya Lahiri. 2008. "Persistent real exchange rates." Journal of International Economics, 76(2): 223-236.

Kollmann, Robert. 2001. "The exchange rate in a dynamic-optimizing business cycle model with nominal rigidities: a quantitative investigation." Journal of International Economics, 55(2): $243-262$.

Martínez-García, Enrique, and Jens Søndergaard. 2013. "Investment and Real Exchange Rates in Sticky Price Models." Macroeconomic Dynamics, 17(2): 195234.

Nakamura, Emi, and Jón Steinsson. 2008. "Five Facts about Prices: A Reevaluation of Menu Cost Models." The Quarterly Journal of Economics, 123(4): 1415-1464.

Rogoff, Kenneth. 1996. "The Purchasing Power Parity Puzzle." Journal of Economic Literature, 34(2): 647-668.

Rudebusch, Glenn D. 2002. "Term structure evidence on interest rate smoothing and monetary policy inertia." Journal of Monetary Economics, 49(6): 1161 - 1187.

Steinsson, Jòn. 2008. "The Dynamic Behavior of the Real Exchange Rate in Sticky Price Models." American Economic Review, 98(1): 519-33.

Taylor, John B. 1993. "Discretion versus policy rules in practice." Carnegie-Rochester Conference Series on Public Policy, 39: 195 - 214. 


\section{Appendix}

\section{A Revisiting Eichenbaum and Evans (1995)}

Eichenbaum and Evans (1995) provided the first empirical evidence on RERs' dynamics conditional on monetary shocks. More specifically, the authors considered how RERs responded to identified monetary shocks using a structural vector autoregression (SVAR) methodology applied to a set of countries' currencies (relative to the dollar). Their results showed that, conditional on monetary shocks, RERs' response are long-lasting and hump-shaped. These set of empirical facts have served as benchmarks for many studies of the dynamic properties of RERs (e.g., Cheung and Lai, 2000, Chari, Kehoe and McGrattan, 2002, Steinsson, 2008, and Carvalho and Nechio, 2011).

We start by assessing whether these properties of the RER still hold using more recent data. In particular, we revisit and update the results of Eichenbaum and Evans (1995), extending their sample and estimating the response of real exchange rates to identified monetary shocks. In particular, we consider Eichenbaum and Evans (1995)'s specification in which dynamic responses are obtained from a 7-variable VAR that includes data on U.S. industrial production $\left(Y^{U S}\right)$, the U.S. consumer price level $\left(P^{U S}\right)$, foreign output $\left(Y^{F o r}\right)$, the foreign interest rate $\left(R^{F o r}\right)$, the federal funds rate $(F F R)$, the ratio of U.S. non-borrowed reserves to total reserves $(N B R X)$, and the real exchange rate $(R E R)$. Real exchange rates are defined as the relative price of the foreign good in terms of the U.S. good, and hence, an increase in $R E R_{t}$ denotes a depreciation of the U.S. real exchange rate. All variables are in logarithms except $R^{\text {For }}$ and FFR.

The sample of countries includes the United Kingdom, Japan, Switzerland, France, Germany, and Italy. The monthly data ranges from January 1974 to December 2007. Seasonally adjusted industrial production and consumer price index data for each country are obtained from the International Financial Statistics database. Foreign interest rates are measured by the interbank rates for all countries except for the United Kingdom and Japan, for which we use 3-month treasury bill rates. Foreign interest rates were obtained from the St. Louis Fed FRED database. Nominal exchange rate series were collected from Bloomberg. Non-borrowed reserves (Adjusted Non-borrowed Reserves Plus Extended Credit) and total reserves (Adjusted Reserves of Depository Institutions) were obtained from FRED. Impulse response functions are calculated assuming a Wold ordering of $\left\{Y^{U S}, P^{U S}, Y^{F o r}, R^{F o r}, F F R, N B R X, R E R\right\}$. The monetary policy shock is identified as the component of the innovation in $F F R_{t}$ that is orthogonal to $Y_{t}^{U S}, P_{t}^{U S}, Y_{t}^{F o r}$, and $R_{t}^{F o r}$. For each country, we select the number of lags in the VAR 
based on the Bayesian Information Criterion (BIC), which yields 2 lags for all countries in our sample.

Figure A1 shows the resulting impulse response functions of real exchange rates of each country in response to a shock to the Federal Funds Rate. The figure corroborates the findings of Eichenbaum and Evans (1995). The impulse response functions exhibit a clear hump-shaped response, and the effects of monetary shocks are quite long-lasting, with the median half-life of these effects across this sample of countries ranging from approximately 4 to 8 years.

Table A1 complements Figure A1 by providing real exchange rate moments implied by their estimation. The table confirms that the response of real exchange rates to monetary shocks are long-lasting and hump-shaped. While Eichenbaum and Evans (1995) included the estimated impulse response functions, they did not report real exchange rate moments implied by their estimation. For a closer comparison to their results, we constrained our sample from January 1974 to May 1990, as in Eichenbaum and Evans (1995), reestimate the VARs, and calculate implied measures of persistence. In that sample, the impulse response functions yield median $\mathcal{H L}, \mathcal{Q L}, \mathcal{U L}$, and $\mathcal{C} \mathcal{I R}$ of $62,65,55$ and 130 months, respectively. ${ }^{14}$

Table A1: Real exchange rate persistence by country: update to Eichenbaum and Evans (1995)

\begin{tabular}{lcccccc}
\hline \hline $\begin{array}{l}\text { Persistence } \\
\text { measures: }\end{array}$ & United Kingdom & Japan & Switzerland & Germany & France & Italy \\
$\mathcal{H} \mathcal{L}$ & 103 & 53 & 82 & 106 & 104 & 104 \\
$\mathcal{Q} \mathcal{L}$ & 124 & 55 & 153 & 121 & 121 & 137 \\
$\mathcal{U} \mathcal{L}$ & 36 & 48 & 51 & 77 & 84 & 72 \\
$\mathcal{C} \mathcal{I} \mathcal{R}$ & 140 & 39 & 163 & 168 & 248 & 177 \\
$\rho_{1}$ & 0.8 & 0.8 & 0.8 & 0.8 & 0.9 & 0.8 \\
\hline \hline
\end{tabular}

Table A2 reports the cross-country median RER moments conditional on monetary shocks, in addition to the results for different versions of the model. In analogy to the exercise of Table 1, the parameter $\rho_{v}$ of the multisector economy with persistent monetary shocks only (second column) is calibrated to roughly match the moments of RERs conditional on identified monetary shocks. Given the value of this parameter, the other model simulations, reported in columns 3 to 7 , are meant to illustrate the effects of policy inertia. All other parameters are unchanged relative to Section 2.2 .

To obtain the first-order autocorrelation $\left(\rho_{1}\right)$ and volatility of real exchange rates conditional

\footnotetext{
${ }^{14}$ All VARs are estimated with 1 lag as suggested by the Bayesian Information Criteria. Eichenbaum and Evans (1995) includes 6 lags in each VAR. Persistence measures obtained when estimating VARs with 6 lags (instead of $1 \mathrm{lag}$ ) are unchanged.
} 
Figure A1: Real exchange rates response to a monetary shock
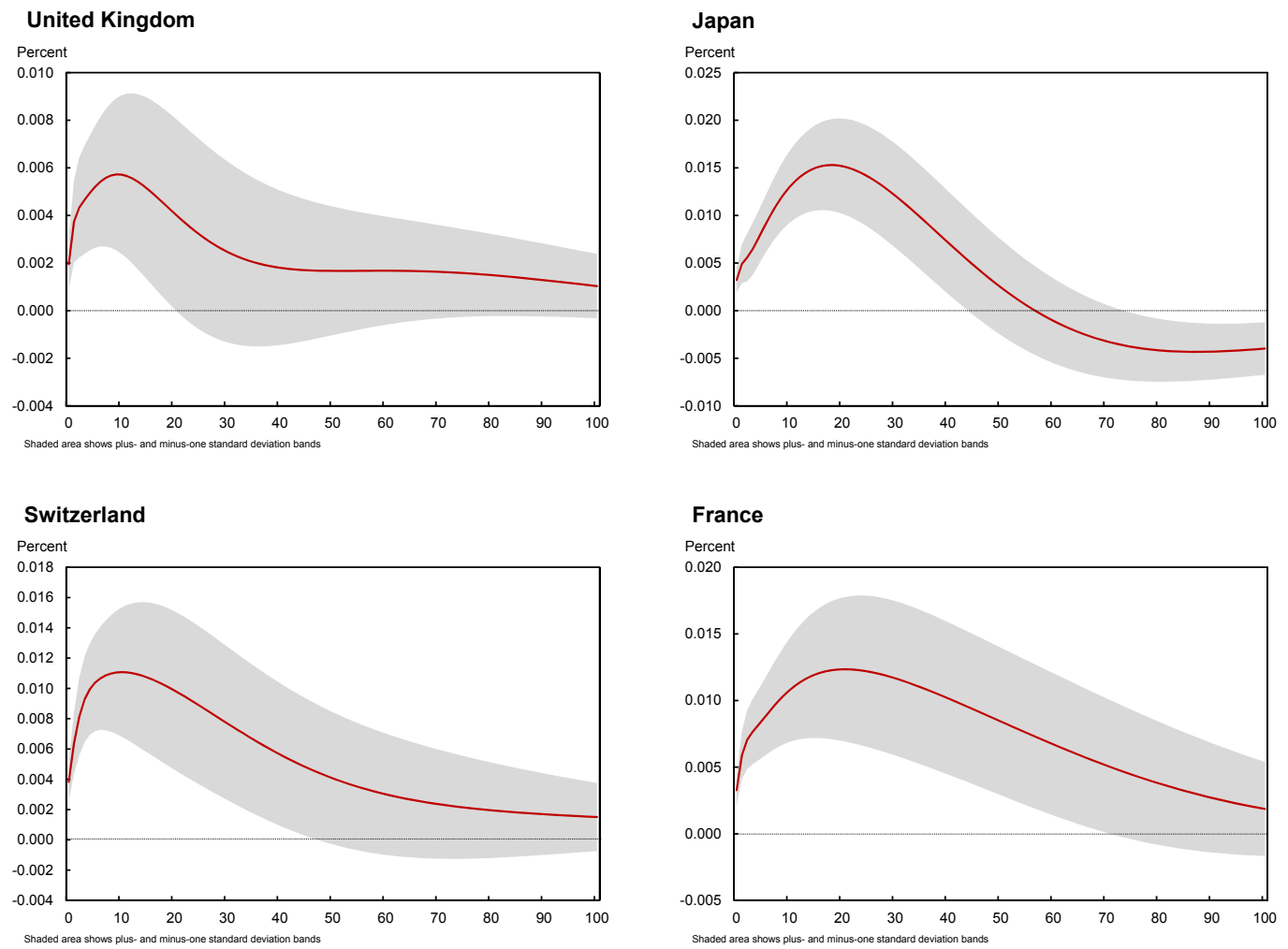

\section{France}

Percent
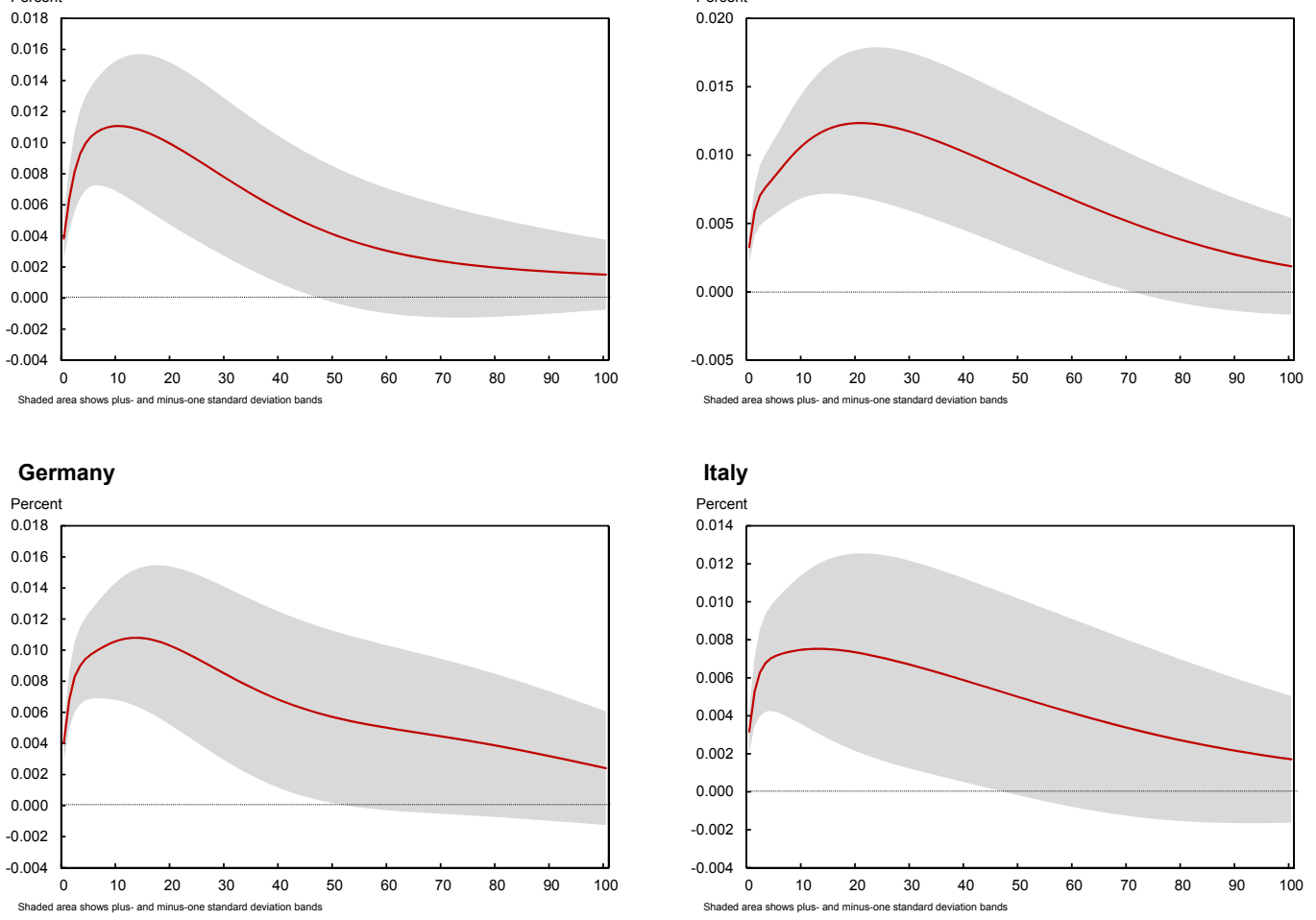
Table A2: Conditional empirical moments and alternative monetary policy rules

\begin{tabular}{|c|c|c|c|c|c|c|c|}
\hline \multirow[b]{2}{*}{$\begin{array}{l}\text { Persistence } \\
\text { measures: }\end{array}$} & \multirow{2}{*}{$\begin{array}{c}\text { Data } \\
(1)\end{array}$} & \multicolumn{3}{|c|}{ Multisector economy } & \multicolumn{3}{|c|}{ One-sector economy } \\
\hline & & $\begin{array}{c}\rho_{v}=.9865 \\
\rho_{i}=0 \\
(2)\end{array}$ & $\begin{array}{c}\rho_{v}=0 \\
\rho_{i}=.9865 \\
(3)\end{array}$ & $\begin{array}{c}\rho_{v}=.9865 \\
\rho_{i}=.9865 \\
\text { (4) }\end{array}$ & $\begin{array}{c}\rho_{v}=.9865 \\
\rho_{i}=0 \\
(5)\end{array}$ & $\begin{array}{c}\rho_{v}=0 \\
\rho_{i}=.9865 \\
\quad(6)\end{array}$ & $\begin{array}{c}\rho_{v}=.9865 \\
\rho_{i}=.9865 \\
(7)\end{array}$ \\
\hline $\mathcal{H} \mathcal{L}$ & 104 & 102 & 7 & 8 & 51 & 4 & 4 \\
\hline $\mathcal{Q} \mathcal{L}$ & 123 & 156 & 20 & 25 & 102 & 8 & 9 \\
\hline $\mathcal{U L}$ & 62 & 45 & 0 & 0 & 0 & 0 & 0 \\
\hline $\mathcal{C I R}$ & 166 & 139 & 16 & 24 & 74 & 6 & 7 \\
\hline$\rho_{1}$ & 0.8 & 0.9 & 0.7 & 0.6 & 0.8 & 0.6 & 0.5 \\
\hline
\end{tabular}

on monetary shocks, we use the identified shock obtained from the estimated structural VAR to construct counterfactual series for the real exchange rate and the U.S. industrial production that are driven only by monetary shocks. The conditional first-order autocorrelation is, then, based on the HP-filtered versions of the resulting RER and U.S. industrial production series, averaged over three-month periods to obtain quarterly data.

A comparison between the first columns of Tables 1 and A2 show that, conditional on monetary shocks, RER persistence measures are even larger than the unconditional ones. The cross-country median half life of deviations of RER from parity, for example, reaches 8 years, well above the (unconditional) "consensus" of 3-5 years. While both the time sample and the set of countries vary between these two aforementioned columns, unconditional persistence measures using the same dataset used to construct the statistics reported in Table A2 yield similar statistics to the unconditional moments reported in Table $1 .^{15}$

Despite the differences between the conditional and the unconditional measures of persistence reported in Tables 1 and A2, when focusing on the model-implied moments, the main lessons from Table 1 remain. Multisector models significantly increase real exchange rate persistence when compared to their one-sector counterparts. More importantly, a comparison among the three versions of the multisector economies reported in Table A2 confirms that the ability of the multisector model to generate empirically plausible RER dynamics disappears when the policy rate features a strong interest rate smoothing component.

\footnotetext{
${ }^{15}$ More specifically, estimating a simple autoregressive (AR) process on the same sample used to estimate the VAR yields median $\mathcal{H} \mathcal{L}, \mathcal{Q L}, \mathcal{U L}$, and $\mathcal{C} \mathcal{I R}$ of $44,70,17$ and 59 months, respectively. For each country, we estimate AR processes with 2 lags, as indicated by the BIC.
} 


\section{B Details on analytical results and proofs}

\section{B.1 Simplified one-sector economy}

To obtain an analytical solution, we simplify our two-country multisector economy. We abstract from heterogeneity and assume a one-sector economy with no home bias $(\omega=0.5)$, constant returns to labor $(\chi=1)$, and infinite Frisch elasticity of labor supply $(\gamma=0)$. As in Engel (2012), we rewrite all variables as the difference between the Home and Foreign counterparts.

\section{B.1.1 Prices and outputs}

A one-sector economy yields:

$$
\begin{gathered}
p_{t}=\omega p_{H, t}+(1-\omega) p_{F, t}, \\
p_{t}^{*}=\omega p_{F, t}^{*}+(1-\omega) p_{H, t}^{*}, \\
p_{H t}=\alpha x_{H, t}+(1-\alpha) p_{H, t-1}, \\
p_{F, t}=\alpha x_{F, t}+(1-\alpha) p_{F, t-1}, \\
p_{H, t}^{*}=\alpha x_{H, t}^{*}+(1-\alpha) p_{H, t-1}^{*}, \\
p_{F, t}^{*}=\alpha x_{F, t}^{*}+(1-\alpha) p_{F, t-1}^{*} .
\end{gathered}
$$

And for the intermediate outputs, we have:

$$
\begin{gathered}
y_{H, j, t+s}=y_{t+s}-\theta\left[p_{H, j, t}-p_{H, t+s}\right]-\rho\left[p_{H, t+s}-p_{t+s}\right], \\
y_{F, j, t+s}=y_{t+s}-\theta\left[p_{F, j, t}-p_{F, t+s}\right]-\rho\left[p_{F, t+s}-p_{t+s}\right], \\
y_{H, j, t+s}^{*}=y_{t+s}^{*}-\theta\left[p_{H, j, t}^{*}-p_{H, t+s}^{*}\right]-\rho\left[p_{H, t+s}^{*}-p_{t+s}^{*}\right], \\
y_{F, j, t+s}^{*}=y_{t+s}^{*}-\theta\left[p_{F, j, t}^{*}-p_{F, t+s}^{*}\right]-\rho\left[p_{F, t+s}^{*}-p_{t+s}^{*}\right],
\end{gathered}
$$

for all times $t+s$ for which the price set at $t$ is still in effect.

For the output aggregations, we have:

$$
\begin{gathered}
y_{t}=\omega y_{H, t}+(1-\omega) y_{F, t}, \\
y_{t}^{*}=\omega y_{F, t}^{*}+(1-\omega) y_{H, t}^{*}, \\
\omega y_{H, t}+(1-\omega) y_{H, t}^{*}=\chi n_{t}=n_{t},
\end{gathered}
$$




$$
\begin{gathered}
\omega y_{F, t}^{*}+(1-\omega) y_{F, t}=\chi n_{t}^{*}=n_{t}, \\
y_{H, t}=\int_{0}^{1} y_{H, j, t} d j, \\
y_{F, t}=\int_{0}^{1} y_{F, j, t} d j, \\
y_{F, t}^{*}=\int_{0}^{1} y_{F, j, t}^{*} d j, \\
y_{H, t}^{*}=\int_{0}^{1} y_{H, j, t}^{*} d j .
\end{gathered}
$$

The marginal cost is such that (recall $\chi=1)$ :

$$
m c_{t}=w_{t}-p_{t}=\sigma c_{t}+\gamma n_{t} .
$$

Loglinearizing the Euler equation yields:

$$
i_{t}=E_{t}\left(\sigma\left(c_{t+1}-c_{t}\right)+p_{t+1}-p_{t}\right) .
$$

For the real exchange rate, we have:

$$
q_{t}=\sigma\left(c_{t}-c_{t}^{*}\right)
$$

Loglinearizing the equation for the prices set by firms when they are called to adjust: ${ }^{16}$

$$
\begin{gathered}
x_{H, t}=\left(1-\beta\left(1-\alpha_{k}\right)\right) E_{t} \sum_{j=0}^{\infty} \beta^{j}(1-\alpha)^{j}\left(p_{t+j}+m c_{t+j}\right), \\
x_{F, t}=\left(1-\beta\left(1-\alpha_{k}\right)\right) E_{t} \sum_{j=0}^{\infty} \beta^{j}(1-\alpha)^{j}\left(p_{t+j}+q_{t+j}+m c_{t+j}^{*}\right), \\
x_{H, t}^{*}=(1-\beta(1-\alpha)) E_{t} \sum_{j=0}^{\infty} \beta^{j}(1-\alpha)^{j}\left(p_{t+j}^{*}-q_{t+j}+m c_{t+j}\right), \\
x_{F, t}^{*}=(1-\beta(1-\alpha)) E_{t} \sum_{j=0}^{\infty} \beta^{j}(1-\alpha)^{j}\left(p_{t+j}^{*}+m c_{t+j}^{*}\right) .
\end{gathered}
$$

\footnotetext{
${ }^{16}$ Although marginal costs are potentially firm-specific due to (potentially) decreasing returns to scale, in each sector, firms that adjust face the same conditional distribution for all future variables that matter for price setting, including marginal costs. Thus, we simplify the notation using a price that is common to all adjusting firms, and also a common marginal cost.
} 


\section{B.1.2 Phillips curves}

Using $x_{H, t}-p_{H, t}=\frac{1-\alpha}{\alpha} \pi_{H, t}$ :

$$
\begin{aligned}
x_{H, t} & =\left(1-\beta\left(1-\alpha_{k}\right)\right) E_{t} \sum_{j=0}^{\infty} \beta^{j}(1-\alpha)^{j}\left(p_{t+j}+m c_{t+j}\right) \\
& =(1-\beta(1-\alpha)) E_{t} \sum_{j=0}^{\infty} \beta^{j}(1-\alpha)^{j}\left(p_{t+j}+\sigma c_{t+j}+\gamma n_{t+j}\right) \\
& \Rightarrow \\
\frac{1-\alpha}{\alpha} \pi_{H, t}= & (1-\beta(1-\alpha)) E_{t} \sum_{j=0}^{\infty} \beta^{j}(1-\alpha)^{j}\left(p_{t+j}+\sigma c_{t+j}+\gamma n_{t+j}-p_{t}\right) \\
= & (1-\beta(1-\alpha)) E_{t} \sum_{j=0}^{\infty} \beta^{j}(1-\alpha)^{j}\left(p_{t+j}+\sigma c_{t+j}+\gamma n_{t+j}-\left[p_{H, t+j}-\Sigma_{i=1}^{j} E_{t} \pi_{H, t+i}\right]\right) \\
= & \frac{\alpha(1-\beta(1-\alpha))}{1-\alpha}\left(p_{t}-p_{H, t}+\sigma c_{t}+\gamma n_{t}\right)+\beta(1-\alpha) E_{t} \pi_{H, t+1} \\
& \pi_{H, t}=\frac{\alpha(1-\beta(1-\alpha))}{1-\alpha}\left(p_{t}-p_{H, t}+\sigma c_{t}+\gamma n_{t}\right)+\beta E_{t} \pi_{H, t+1} \\
& =\frac{\alpha(1-\beta(1-\alpha))}{1-\alpha}\left(\frac{1}{\rho}\left(y_{H, t}-y_{t}\right)+\sigma c_{t}+\gamma n_{t}\right)+\beta E_{t} \pi_{H, t+1}
\end{aligned}
$$

Using $x_{F, t}-p_{F, t}=\frac{1-\alpha}{\alpha} \pi_{F, t}$ :

$$
\begin{aligned}
x_{F, t} & =\left(1-\beta\left(1-\alpha_{k}\right)\right) E_{t} \sum_{j=0}^{\infty} \beta^{j}(1-\alpha)^{j}\left(p_{t+j}+q_{t+j}+m c_{t+j}^{*}\right) \\
& \Rightarrow \\
\pi_{F, t} & =\frac{\alpha(1-\beta(1-\alpha))}{1-\alpha}\left(p_{t}-p_{F, t}+\sigma c_{t}^{*}+\gamma n_{t}^{*}+q_{t}\right)+\beta(1-\alpha) E_{t} \pi_{F, t+1} \\
& =\frac{\alpha(1-\beta(1-\alpha))}{1-\alpha}\left(\frac{1}{\rho}\left(y_{F, t}-y_{t}\right)+\sigma c_{t}^{*}+\gamma n_{t}^{*}+q_{t}\right)+\beta E_{t} \pi_{F, t+1}
\end{aligned}
$$

Using $x_{H, t}^{*}-p_{H, t}^{*}=\frac{1-\alpha}{\alpha} \pi_{H, t}^{*}$ :

$$
\begin{aligned}
x_{H, t}^{*} & =(1-\beta(1-\alpha)) E_{t} \sum_{j=0}^{\infty} \beta^{j}(1-\alpha)^{j}\left(p_{t+j}^{*}-q_{t+j}+m c_{t+j}\right) \\
& \Rightarrow \\
\pi_{H, t}^{*} & =\frac{\alpha(1-\beta(1-\alpha))}{1-\alpha}\left(p_{t}^{*}-p_{H, t}^{*}+\sigma c_{t}+\gamma n_{t}-q_{t}\right)+\beta E_{t} \pi_{H, t+1} \\
& =\frac{\alpha(1-\beta(1-\alpha))}{1-\alpha}\left(\frac{1}{\rho}\left(y_{H, t}^{*}-y_{t}^{*}\right)+\sigma c_{t}+\gamma n_{t}-q_{t}\right)+\beta E_{t} \pi_{H, t+1}
\end{aligned}
$$




$$
\begin{aligned}
x_{F, t}^{*} & =(1-\beta(1-\alpha)) E_{t} \sum_{j=0}^{\infty} \beta^{j}(1-\alpha)^{j}\left(p_{t+j}^{*}+m c_{t+j}^{*}\right) \\
& \Rightarrow \\
\pi_{F, t}^{*} & =\frac{\alpha(1-\beta(1-\alpha))}{1-\alpha}\left(p_{t}^{*}-p_{F, t}^{*}+\sigma c_{t}^{*}+\gamma n_{t}^{*}\right)+\beta E_{t} \pi_{F, t+1}^{*} \\
& =\frac{\alpha(1-\beta(1-\alpha))}{1-\alpha}\left(\frac{1}{\rho}\left(y_{F, t}^{*}-y_{t}^{*}\right)+\sigma c_{t}^{*}+\gamma n_{t}^{*}\right)+\beta E_{t} \pi_{F, t+1}^{*}
\end{aligned}
$$

From these equations we get:

$$
\begin{aligned}
\pi_{t}= & \omega \pi_{H, t}+(1-\omega) \pi_{F, t} \\
= & \omega\left[\left(\frac{1}{\rho}\left(y_{H, t}-y_{t}\right)+\sigma c_{t}+\gamma n_{t}\right)+\beta E_{t} \pi_{H, t+1}\right] \\
& +(1-\omega)\left[\left(\frac{1}{\rho}\left(y_{F, t}-y_{t}\right)+\sigma c_{t}^{*}+\gamma n_{t}^{*}+q_{t}\right)+\beta E_{t} \pi_{F, t+1}\right], \\
\pi_{t}^{*}= & \omega \pi_{F, t}^{*}+(1-\omega) \pi_{H, t}^{*} \\
= & \omega\left[\left(\frac{1}{\rho}\left(y_{F, t}^{*}-y_{t}^{*}\right)+\sigma c_{t}^{*}+\gamma n_{t}^{*}\right)+\beta E_{t} \pi_{F, t+1}^{*}\right] \\
& +(1-\omega)\left[\left(\frac{1}{\rho}\left(y_{H, t}^{*}-y_{t}^{*}\right)+\sigma c_{t}+\gamma n_{t}-q_{t}\right)+\beta E_{t} \pi_{H, t+1}\right],
\end{aligned}
$$

Therefore:

$$
\begin{aligned}
\pi_{t}-\pi_{t}^{*}= & \omega\left[\frac{\alpha(1-\beta(1-\alpha))}{1-\alpha}\left(\frac{1}{\rho}\left(y_{H, t}-y_{t}\right)+\sigma c_{t}+\gamma n_{t}\right)+\beta E_{t} \pi_{H, t+1}\right] \\
& -\omega\left[\frac{\alpha(1-\beta(1-\alpha))}{1-\alpha}\left(\frac{1}{\rho}\left(y_{F, t}^{*}-y_{t}^{*}\right)+\sigma c_{t}^{*}+\gamma n_{t}^{*}\right)+\beta E_{t} \pi_{F, t+1}^{*}\right] \\
& +(1-\omega)\left[\frac{\alpha(1-\beta(1-\alpha))}{1-\alpha}\left(\frac{1}{\rho}\left(y_{F, t}-y_{t}\right)+\sigma c_{t}^{*}+\gamma n_{t}^{*}+q_{t}\right)+\beta E_{t} \pi_{F, t+1}\right] \\
& -(1-\omega)\left[\frac{\alpha(1-\beta(1-\alpha))}{1-\alpha}\left(\frac{1}{\rho}\left(y_{H, t}^{*}-y_{t}^{*}\right)+\sigma c_{t}+\gamma n_{t}-q_{t}\right)+\beta E_{t} \pi_{H, t+1}\right] .
\end{aligned}
$$

Note that $q_{t}=\sigma\left(c_{t}-c_{t}^{*}\right)$, and:

$$
\begin{aligned}
\omega\left(y_{H, t}-y_{t}\right) & =-(1-\omega)\left(y_{F, t}-y_{t}\right), \\
\omega\left(y_{F, t}^{*}-y_{t}^{*}\right) & =-(1-\omega)\left(y_{H, t}^{*}-y_{t}^{*}\right) .
\end{aligned}
$$


Hence, for $\delta=\frac{\bar{\alpha}(1-\beta(1-\bar{\alpha}))}{1-\bar{\alpha}}, \bar{\alpha}=\Sigma_{s=1}^{S} f_{s} \alpha_{s}$, we can rewrite $\pi_{t}-\pi_{t}^{*}$ :

$$
\pi_{t}-\pi_{t}^{*}=\delta q_{t}+(2 \omega-1) \gamma \delta\left(n_{t}-n_{t}^{*}\right)+\beta E_{t}\left(\pi_{t+1}-\pi_{t+1}^{*}\right) .
$$

Assuming no home bias, $\omega=(1-\omega)$, and setting $\gamma=0$ yield:

$$
\pi_{t}-\pi_{t}^{*}=\delta q_{t}+\beta E_{t}\left(\pi_{t+1}-\pi_{t+1}^{*}\right)
$$

\section{B.1.3 Euler equations (demand side):}

The Euler equations for Home and Foreign equal:

$$
\begin{aligned}
i_{t} & =\sigma E_{t} c_{t+1}-\sigma c_{t}+E_{t} \pi_{t+1}, \\
i_{t}^{*} & =\sigma E_{t} c_{t+1}^{*}-\sigma c_{t}^{*}+E_{t} \pi_{t+1}^{*}, \\
\Rightarrow & \\
i_{t}-i_{t}^{*} & =E_{t} q_{t+1}-q_{t}+E_{t}\left(\pi_{t+1}-\pi_{t+1}^{*}\right) .
\end{aligned}
$$

\section{B.1.4 Monetary policy}

We simplify monetary policy such that the interest rate rule for Home equals:

$$
i_{t}=\rho_{i} i_{t-1}+\left(1-\rho_{i}\right) \phi_{\pi} \pi_{t}+v_{t}
$$

where we assume that the exogenous component of the interest rate $\left(v_{t}\right)$ follows an autoregressive process such that $v_{t}=\rho_{v} v_{t-1}+\varepsilon_{t}^{v}, \rho_{v} \in[0,1)$, and $\varepsilon_{t}^{v}$ is i.i.d.

Finally, we assume throughout that monetary policy in Foreign follows the same rule as in Home, and that monetary shocks are uncorrelated across the two countries.

\section{B.1.5 Proofs of propositions and corollaries}

Proposition 1 The solution to the simplified three-equation model (equations 8-10) takes the form:

$$
\begin{aligned}
q_{t} & =\varphi_{q v} v_{t}+\gamma_{q} d i_{t-1}, \\
d \pi_{t} & =\varphi_{\pi v} v_{t}+\gamma_{\pi} d i_{t-1},
\end{aligned}
$$

where $\varphi_{q v}, \varphi_{\pi v}, \gamma_{\pi}, \gamma_{q}$ are negative coefficients. 
Proof. Consider the model as deviations between Home and Foreign, where any variable labeled as $d x_{t}$ corresponds to $d x_{t}=x_{t}-x_{t}^{*}$.

We depart from the main-text equations (8), (9) and (10) and note that $E_{t}\left(v_{t+1}\right)=\rho_{v} v_{t}$. Replacing (10) on (9) yields:

$$
q_{t}+\left(1-\rho_{i}\right) \phi_{\pi} d \pi_{t}=E_{t} q_{t+1}+E_{t} d \pi_{t+1}-\rho_{i} d i_{t-1}-v_{t} .
$$

Our system of equations is such that:

$$
\begin{gathered}
q_{t}+\left(1-\rho_{i}\right) \phi_{\pi} d \pi_{t}=+E_{t} q_{t+1}+E_{t} d \pi_{t+1}-\rho_{i} d i_{t-1}-v_{t} \\
-\delta q_{t}+d \pi_{t}=+\beta E_{t} d \pi_{t+1} \\
\Rightarrow \\
\left(\begin{array}{c}
q_{t} \\
d \pi_{t}
\end{array}\right)=\Omega\left(\begin{array}{cc}
1 & 1-\beta\left(1-\rho_{i}\right) \phi_{\pi} \\
\delta & \beta+\delta
\end{array}\right)\left(\begin{array}{c}
E_{t} q_{t+1} \\
E_{t} d \pi_{t+1}
\end{array}\right)+\Omega\left(\begin{array}{c}
-1 \\
-\delta
\end{array}\right)\left(\rho_{i} d i_{t-1}+v_{t}\right) \\
\Omega=\frac{1}{1+\delta\left(1-\rho_{i}\right) \phi_{\pi}}
\end{gathered}
$$

Guess the solution will take the form:

$$
\begin{aligned}
q_{t} & =\varphi_{q v} v_{t}+\gamma_{q} d i_{t-1}, \\
d \pi_{t} & =\varphi_{\pi v} v_{t}+\gamma_{\pi} d i_{t-1} .
\end{aligned}
$$

Starting from $q_{t}$ and substituting for $d \pi_{t}$ and $d i_{t}$ :

$$
\begin{aligned}
q_{t}= & -\left(1-\rho_{i}\right) \phi_{\pi} d \pi_{t}+E_{t} q_{t+1}+E_{t} d \pi_{t+1}-\rho_{i} d i_{t-1}-v_{t} \\
= & {\left[-\left(1-\rho_{i}\right) \phi_{\pi} \varphi_{\pi v}+\varphi_{q v} \rho_{v}+\gamma_{q}\left(1-\rho_{i}\right) \phi_{\pi} \varphi_{\pi v}+\gamma_{q}+\varphi_{\pi v} \rho_{v}+\gamma_{\pi}\left(1-\rho_{i}\right) \phi_{\pi} \varphi_{\pi v}+\gamma_{\pi}-1\right] v_{t} } \\
& +\left[-\left(1-\rho_{i}\right) \phi_{\pi} \gamma_{\pi}+\gamma_{q} \rho_{i}+\gamma_{q}\left(1-\rho_{i}\right) \phi_{\pi} \gamma_{\pi}+\gamma_{\pi} \rho_{i}+\gamma_{\pi}\left(1-\rho_{i}\right) \phi_{\pi} \gamma_{\pi}-\rho_{i}\right] d i_{t-1} .
\end{aligned}
$$

Starting from $d \pi_{t}$ and substituting for $q_{t}$ and $d i_{t}$ :

$$
\begin{aligned}
d \pi_{t}= & \delta q_{t}+\beta E_{t} d \pi_{t+1} \\
= & {\left[\beta \varphi_{\pi v} \rho_{v}+\beta \gamma_{\pi}\left(1-\rho_{i}\right) \phi_{\pi} \varphi_{\pi v}+\beta \gamma_{\pi}+\delta \varphi_{q v}\right] v_{t} } \\
& +\left[\beta \gamma_{\pi} \rho_{i}+\beta \gamma_{\pi}\left(1-\rho_{i}\right) \phi_{\pi} \gamma_{\pi}+\delta \gamma_{q}\right] d i_{t-1} .
\end{aligned}
$$


Matching coefficients, we have 4 equations and 4 variables:

$$
\begin{aligned}
\varphi_{q v}= & -\left(1-\rho_{i}\right) \phi_{\pi} \varphi_{\pi v}+\varphi_{q v} \rho_{v}+\gamma_{q}\left(1-\rho_{i}\right) \phi_{\pi} \varphi_{\pi v}+\gamma_{q} \\
& +\varphi_{\pi v} \rho_{v}+\gamma_{\pi}\left(1-\rho_{i}\right) \phi_{\pi} \varphi_{\pi v}+\gamma_{\pi}-1, \\
\varphi_{\pi v}= & \beta \varphi_{\pi v} \rho_{v}+\beta \gamma_{\pi}\left(1-\rho_{i}\right) \phi_{\pi} \varphi_{\pi v}+\beta \gamma_{\pi}+\delta \varphi_{q v}, \\
\gamma_{q}= & -\left(1-\rho_{i}\right) \phi_{\pi} \gamma_{\pi}+\gamma_{q} \rho_{i}+\gamma_{q}\left(1-\rho_{i}\right) \phi_{\pi} \gamma_{\pi}+\gamma_{\pi} \rho_{i}+\gamma_{\pi}\left(1-\rho_{i}\right) \phi_{\pi} \gamma_{\pi}-\rho_{i}, \\
\gamma_{\pi}= & \beta \gamma_{\pi} \rho_{i}+\beta \gamma_{\pi}\left(1-\rho_{i}\right) \phi_{\pi} \gamma_{\pi}+\delta \gamma_{q} .
\end{aligned}
$$

Corollary 1 Under the assumptions above, the cumulative impulse response function of the real exchange rate equals:

$$
\begin{aligned}
\mathcal{C} \mathcal{I R}(q) & =\frac{1}{1-\rho_{v}}+\frac{1}{\left(1-\rho_{v}\right)} \frac{\gamma_{q}}{\varphi_{q v}} \frac{\left(\left(1-\rho_{i}\right) \phi_{\pi} \varphi_{\pi v}+1\right)}{\left(1-\left(\rho_{i}+\left(1-\rho_{i}\right) \phi_{\pi} \gamma_{\pi}\right)\right)} \\
& =\underbrace{\frac{1}{1-\rho_{v}}}_{>0}(1+\underbrace{\frac{\gamma_{q}}{\varphi_{q v}}}_{>0} \underbrace{\left.\frac{\overbrace{\left(\left(1-\rho_{i}\right) \phi_{\pi} \varphi_{\pi v}+1\right)}^{\left(1-\rho_{i}-\left(1-\rho_{i}\right) \phi_{\pi} \gamma_{\pi}\right)}}{\left(1-\rho_{i}\right.}\right)}_{>0})
\end{aligned}
$$

Proof. Using the above equations, we can calculate the cumulative impulse response function of $q_{t}$ following a unit monetary policy shock.

$$
\operatorname{CIR}\left(q_{t}\right)=\sum_{n=1}^{N} \frac{q_{n}}{q_{1}}
$$

where:

$$
\begin{aligned}
q_{t} & =\varphi_{q v} v_{t}+\gamma_{q} d i_{t-1}, \\
d \pi_{t} & =\varphi_{\pi v} v_{t}+\gamma_{\pi} d i_{t-1}, \\
i_{t} & =\rho_{i} i_{t-1}+\left(1-\rho_{i}\right) \phi_{\pi} \pi_{t}+v_{t} .
\end{aligned}
$$

Solving the equation for interest rate forward:

$$
i_{n-1}=\left(\left(1-\rho_{i}\right) \phi_{\pi} \varphi_{\pi v}+1\right) \sum_{i=0}^{n-1}\left(\rho_{i}+\left(1-\rho_{i}\right) \phi_{\pi} \gamma_{\pi}\right)^{i} \rho_{v}^{n-1-i}
$$

Replacing the above expression in the main text equation (11) at time $n$ and calculating the 
cumulative impulse response yields:

$$
\begin{aligned}
\underset{N \rightarrow \infty}{C I R(q)} & \rightarrow \sum_{n=1}^{\infty} \frac{q_{n}}{q_{1}}=\sum_{n=1}^{N \rightarrow \infty} \frac{\varphi_{q v} \rho_{v}^{n-1}+\gamma_{q}\left(\left(1-\rho_{i}\right) \phi_{\pi} \varphi_{\pi v}+1\right) \sum_{i=0}^{n-1}\left(\rho_{i}+\left(1-\rho_{i}\right) \phi_{\pi} \gamma_{\pi}\right)^{i} \rho_{v}^{n-1-i}}{\varphi_{q v}} \\
\Rightarrow & \left.=\frac{\frac{\varphi_{q v}}{1-\rho_{v}}+\gamma_{q}\left(\phi_{\pi} \varphi_{\pi v}+1\right) \sum_{n=1}^{\infty}\left[\rho_{v}^{n-1} \frac{1-\left(\frac{\rho_{i}+\left(1-\rho_{i}\right) \phi_{\pi} \gamma_{\pi}}{\rho_{v}}\right)^{n}}{1-\frac{\rho_{i}+\left(1-\rho_{i}\right) \phi_{\pi} \gamma_{\pi}}{\rho_{v}}}\right]}{\varphi_{q v}}\right] \\
C I R(q) & =\underbrace{\frac{1}{1-\rho_{v}}}_{>0}(1+\underbrace{\frac{\gamma_{q}}{\varphi_{q v}}}_{>0} \underbrace{\frac{\left(\left(1-\rho_{i}\right) \phi_{\pi} \varphi_{\pi v}+1\right)}{\left(1-\rho_{i}\right)\left(1-\phi_{\pi} \gamma_{\pi}\right)}}_{>0}),
\end{aligned}
$$

where we used the fact that $-1<\rho_{i}+\left(1-\rho_{i}\right) \phi_{\pi} \gamma_{\pi}<1^{17}$

Corollary 2 For $\rho_{v}^{\text {crit }}=\frac{(1+\beta+\delta)-\sqrt{(1+\beta+\delta)^{2}-4 \beta}}{2 \beta}>0$, whenever $\rho_{v}>\rho_{v}^{\text {crit }}$ introducing policy inertia $\left(\rho_{i}>0\right)$ lowers RER persistence, as measured by $C I R(q)$, relative to the case of persistent monetary policy shocks only.

Proof. When $\rho_{i}=0, \gamma_{q}=\gamma_{\pi}=0$, which implies $C I R(q)=\frac{1}{1-\rho_{v}}$.

Since $\varphi_{q v}, \varphi_{\pi v}, \gamma_{\pi}, \gamma_{q}$ are negative coefficients, the only term that doesn't have a definite sign is $\left(\left(1-\rho_{i}\right) \phi_{\pi} \varphi_{\pi v}+1\right)$. Since $\left(1-\rho_{i}\right) \phi_{\pi}>1$, this term will be negative when $\varphi_{\pi v}<-\frac{1}{\left(1-\rho_{i}\right) \phi_{\pi}}$.

Departing from the solutions for $\varphi_{\pi v}$ and $\varphi_{q v}$ from equations (B.3) and (B.2), respectively, for $\rho_{v}=0$ :

$$
\varphi_{\pi v}=\left[\beta \gamma_{\pi}+\delta\left(\gamma_{q}+\gamma_{\pi}-1\right)\right]\left(1-\rho_{i}\right) \phi_{\pi} \varphi_{\pi v}+\left[\beta \gamma_{\pi}+\delta\left(\gamma_{q}+\gamma_{\pi}-1\right)\right]
$$

Call $A=\left[\beta \gamma_{\pi}+\delta\left(\gamma_{q}+\gamma_{\pi}-1\right)\right]$ to obtain:

$$
\begin{aligned}
\varphi_{\pi v} & =A\left(1-\rho_{i}\right) \phi_{\pi} \varphi_{\pi v}+A \\
\left(1-A\left(1-\rho_{i}\right) \phi_{\pi}\right) \varphi_{\pi v} & =A \\
\varphi_{\pi v} & =\frac{A}{\left(1-A\left(1-\rho_{i}\right) \phi_{\pi}\right)}
\end{aligned}
$$

\footnotetext{
${ }^{17}$ In fact, this term equals the $\mathrm{AR}(1)$ coefficient on $d i_{t}$ in the simplified one-sector model (see the main-text equation (14)), and hence, for versions of the model in which a unique solution exists, $0<\rho_{i}+\left(1-\rho_{i}\right) \phi_{\pi} \gamma_{\pi}<1$.
} 
Note that $A$ is negative since $\gamma_{\pi}$ is negative, $\rho_{i}<1$, and $\delta>0$. Therefore:

$$
\varphi_{\pi v}=\frac{A}{\left(1-A\left(1-\rho_{i}\right) \phi_{\pi}\right)}>-\frac{1}{\left(1-\rho_{i}\right) \phi_{\pi}}
$$

Hence, when $\rho_{v}=0$, we find that $\varphi_{\pi v}$ is always larger than $-\frac{1}{\left(1-\rho_{i}\right) \phi_{\pi}}$.

More generally,

$$
\begin{aligned}
\varphi_{q v}= & -\left(1-\rho_{i}\right) \phi_{\pi} \varphi_{\pi v}+\varphi_{q v} \rho_{v}+\gamma_{q}\left(1-\rho_{i}\right) \phi_{\pi} \varphi_{\pi v}+\gamma_{q}+\varphi_{\pi v} \rho_{v}+\gamma_{\pi}\left(1-\rho_{i}\right) \phi_{\pi} \varphi_{\pi v}+\gamma_{\pi}-1 \\
\Rightarrow & \\
\left(1-\rho_{v}\right) \varphi_{q v}= & \left(\gamma_{q}+\gamma_{\pi}-1\right)\left(1-\rho_{i}\right) \phi_{\pi} \varphi_{\pi v}+\rho_{v} \varphi_{\pi v}+\left(\gamma_{\pi}+\gamma_{q}-1\right) \\
\varphi_{\pi v}= & \beta \rho_{v} \varphi_{\pi v}+\beta \gamma_{\pi}+\beta \gamma_{\pi}\left(1-\rho_{i}\right) \phi_{\pi} \varphi_{\pi v}+\delta \varphi_{q v} \\
\Rightarrow & \\
\left(1-\rho_{v}\right) \varphi_{\pi v}= & {\left[\left(1-\rho_{v}\right) \beta+\delta\right] \rho_{v} \varphi_{\pi v}+\left[\left(1-\rho_{v}\right) \beta \gamma_{\pi}+\delta\left(\gamma_{q}+\gamma_{\pi}-1\right)\right]\left(1-\rho_{i}\right) \phi_{\pi} \varphi_{\pi v} } \\
& \quad+\left[\left(1-\rho_{v}\right) \beta \gamma_{\pi}+\delta\left(\gamma_{\pi}+\gamma_{q}-1\right)\right]
\end{aligned}
$$

Call $B=\left[\left(1-\rho_{v}\right) \beta \gamma_{\pi}+\delta\left(\gamma_{\pi}+\gamma_{q}-1\right)\right]<0$ to obtain:

$$
\varphi_{\pi v}=\frac{B}{\left\{\left(1-\rho_{v}\right)-\left[\left(1-\rho_{v}\right) \beta+\delta\right] \rho_{v}-B\left(1-\rho_{i}\right) \phi_{\pi}\right\}}
$$

Since $\varphi_{\pi v}<0$, we know that the denominator of the above expression is positive. Therefore, $\varphi_{\pi v}<-\frac{1}{\left(1-\rho_{i}\right) \phi_{\pi}}$ when:

$$
\begin{aligned}
\frac{B}{\left\{\left(1-\rho_{v}\right)-\left[\left(1-\rho_{v}\right) \beta+\delta\right] \rho_{v}-B\left(1-\rho_{i}\right) \phi_{\pi}\right\}} & <-\frac{1}{\left(1-\rho_{i}\right) \phi_{\pi}} \\
B\left(1-\rho_{i}\right) \phi_{\pi} & <-\left(1-\rho_{v}\right)+\left[\left(1-\rho_{v}\right) \beta+\delta\right] \rho_{v}+B\left(1-\rho_{i}\right) \phi_{\pi} \\
+\beta \rho_{v}^{2}-(1+\beta+\delta) \rho_{v}+1 & <0
\end{aligned}
$$

Solving the above expression for $\rho_{v}$ :

$$
\rho_{v}=\frac{(1+\beta+\delta) \pm \sqrt{(1+\beta+\delta)^{2}-4 \beta}}{2 \beta}
$$


And $\varphi_{\pi v}<-\frac{1}{\left(1-\rho_{i}\right) \phi_{\pi}}$, as long as:

$$
\frac{(1+\beta+\delta)-\sqrt{(1+\beta+\delta)^{2}-4 \beta}}{2 \beta}<\rho_{v}<1
$$

where $\frac{\bar{\alpha}(1-\beta(1-\bar{\alpha}))}{1-\bar{\alpha}}=\delta$.

Under our parameterization, $\varphi_{\pi v}<-2 / 3$ when $\rho_{v}>0.7888$. Note that $\frac{(1+\beta+\delta)+\sqrt{(1+\beta+\delta)^{2}-4 \beta}}{2 \beta}>$ 1 , since $\Delta=(1+\beta+\delta)^{2}-4 \beta>0$ and $\frac{(1+\beta+\delta)}{2 \beta}>1$.

Corollary 3 Under the simplified model assumptions, introducing policy inertia $\left(\rho_{i}>0\right)$ into to the model unequivocally increases the rate of convergence of dit back to its steady state, while it reduces the convergence of $d \pi_{t}$ when $\rho_{v}>\rho_{v}^{\text {crit }}$. Therefore, the convergence speed of the real exchange rate back to steady state increases.

Intuitively, in this simple one-sector model, if the policy rule only exhibits persistent shocks, $\rho_{v}$ is the only source of exogenous persistence and the dynamics of all variables are determined by its level. When policy inertia is included in the model, the dynamics of all variables are also determined by the response of interest rates to shocks, and will depend on $\rho_{v}$ as well as on the coefficients in the model solution from equations (11) and (12). Corollaries 1-3 show that, when shock persistence is high, introducing inertia into the model alters the dynamics in such a way that the effects of monetary shocks on real exchange rate die out more quickly.

Proof. In a general equilibrium model, the dynamics of the model depend on the response of all variables. The response of the nominal interest rate, however, can change substantially with the level of $\rho_{v}$. In particular, for levels of $\rho_{v}>\rho_{v}^{c r i t}$, the response of the nominal rate will be such that it moves in the opposite direction from the shock. That is, for an expansionary shock, $\left(v_{t}<0\right)$, for $\rho_{v}>\rho_{v}^{c r i t}$, the nominal rate increases on impact.

This will hold whether or not the policy rule exhibits inertia. However, inertia will affect the speed of convergence of the nominal rate, and therefore, through the Euler equation, the speed of convergence of the real exchange rate.

To see this, first note that, the dynamics of the real exchange rate is determined by the responses of the nominal rate and inflation through the Euler equation. Solving (the loglinearized version of) the Euler equation (9) forward yields:

$$
q_{t}=-\sigma^{-1} E_{t} \sum_{j=0}^{\infty}\left(d i_{t+j}-E_{t+j} d \pi_{t+1+j}\right) .
$$

Therefore, changes on the speed of convergence of the nominal rate and inflation back to their 
steady state will affect the dynamics of the real exchange rate. ${ }^{18}$

Departing from the policy rule and the guessed solution (equations (10)-(12)):

$$
\begin{aligned}
d i_{t} & =\rho_{i} d i_{t-1}+\left(1-\rho_{i}\right) \phi_{\pi} d \pi_{t}+v_{t} \\
& =\left[\rho_{i}+\left(1-\rho_{i}\right) \phi_{\pi} \gamma_{\pi}\right] d i_{t-1}+\underbrace{\left[1+\left(1-\rho_{i}\right) \phi_{\pi} \varphi_{\pi v}\right]}_{\gtrless 0} v_{t}
\end{aligned}
$$

Therefore, the incremental step between time $t+j$ and the response on impact are such that:

$$
\frac{d i_{t+j}}{d i_{1}}=\rho_{v}^{j-1}+\underbrace{\left\{\sum_{n=2}^{j}\left[\rho_{i}+\left(1-\rho_{i}\right) \phi_{\pi} \gamma_{\pi}\right]^{n-1} \rho_{v}^{j-n}\right\}}_{>0}
$$

Since the term in curly brackets is positive, adding inertia to the model augments the step between any two periods in the response of the nominal rate. Therefore, adding inertia to the policy rule unequivocally speeds the convergence of $i_{t}$ up.

Turning to the response of inflation:

$$
\begin{aligned}
\frac{d \pi_{t+j+1}}{d \pi_{1}} & =\frac{\varphi_{\pi v} \rho_{v}^{j} v_{1}+\gamma_{\pi}\left[1+\left(1-\rho_{i}\right) \phi_{\pi} \varphi_{\pi v}\right]\left\{\sum_{n=1}^{j}\left[\rho_{i}+\left(1-\rho_{i}\right) \phi_{\pi} \gamma_{\pi}\right]^{n-1} \rho_{v}^{j-n}\right\} v_{1}}{\varphi_{\pi v} v_{1}} \\
& =\rho_{v}^{j}+\underbrace{\frac{\gamma_{\pi}}{\varphi_{\pi v}}}_{>0} \underbrace{\left[1+\left(1-\rho_{i}\right) \phi_{\pi} \varphi_{\pi v}\right]}_{\lessgtr 0} \underbrace{\left\{\sum_{n=1}^{j}\left[\rho_{i}+\left(1-\rho_{i}\right) \phi_{\pi} \gamma_{\pi}\right]^{n-1} \rho_{v}^{j-n}\right\}}_{>0}
\end{aligned}
$$

When inertia is added to the model, the incremental step between time $t+j$ and the response on impact gains an additional term with a sign that depends on $\tilde{\varphi}_{\pi v}$. From Corollary 2, this term is negative when $\rho_{v}>\rho_{\text {crit }}$. Therefore, the speed of convergence of $d \pi_{t}$ back to steady state declines when $\rho_{v}>\rho_{v}^{\text {crit }}$.

\section{B.2 Simplified two-sector economy}

Proposition 2 The solution to the simplified two-sector model takes the form:

$$
\begin{aligned}
d \pi_{t} & =\varphi_{\pi} v_{t}+\gamma_{\pi} d i_{t-1}+\theta_{\pi} d r p_{1, t-1} \\
q_{t} & =\varphi_{q} v_{t}+\gamma_{q} d i_{t-1}+\theta_{q} d r p_{1, t-1} \\
d r p_{1, t} & =\varphi_{p} v_{t}+\gamma_{p} d i_{t-1}+\theta_{p} d r p_{1, t-1}
\end{aligned}
$$

\footnotetext{
${ }^{18}$ This deconstruction was introduced by Steinsson (2008).
} 
where $\varphi_{\pi}, \varphi_{q}, \varphi_{p}, \gamma_{\pi}, \gamma_{q}, \gamma_{p}, \theta_{\pi}, \theta_{q}$, and $\theta_{p}$ are negative coefficients.

Proof. The solution to this problem resembles the one from Section B.1 except that pricing and output equations change to allow for the multisector dimension.

To simplify the problem, we consider an equally-weighted two-sector economy and continue to assume no home bias, $\omega=0.5$, no capital accumulation, and $\chi=1$. As before, we write all variables as the difference between the Home and Foreign counterparts.

Under these assumptions, the Euler equation and the interest rate rules are the same as those reported in Sections B.1.3 and B.1.4, respectively. The Phillips curves, however, need to be rewritten.

Departing from the definitions for prices:

$$
\begin{gathered}
p_{t}=f p_{1, t}+(1-f) p_{2, t}, \\
p_{t}^{*}=f p_{1, t}^{*}+(1-f) p_{2, t}^{*}, \\
p_{1, t}=\omega p_{H, 1, t}+(1-\omega) p_{F, 1, t}, \\
p_{2, t}=\omega p_{H, 2, t}+(1-\omega) p_{F, 2, t}, \\
p_{1, t}^{*}=\omega p_{F, 1, t}^{*}+(1-\omega) p_{H, 1, t}^{*}, \\
p_{2, t}^{*}=\omega p_{F, 2, t}^{*}+(1-\omega) p_{H, 2, t}^{*}, \\
p_{H, s, t}=\alpha x_{H, s, t}+(1-\alpha) p_{H, s, t-1}, \quad s=1,2, \\
p_{F, s, t}=\alpha x_{F, s, t}+(1-\alpha) p_{F, s, t-1}, \quad s=1,2, \\
p_{H, s, t}^{*}=\alpha x_{H, s, t}^{*}+(1-\alpha) p_{H, s, t-1}^{*}, \quad s=1,2, \\
p_{F, s, t}^{*}=\alpha x_{F, s, t}^{*}+(1-\alpha) p_{F, s, t-1}^{*}, \quad s=1,2,
\end{gathered}
$$

Intermediate outputs are such that:

$$
\begin{aligned}
y_{H, j, s, t+i} & =y_{t+i}-\theta\left[p_{H, j, s, t}-p_{H, s, t+i}\right]-\rho\left[p_{H, s, t+i}-p_{s, t+i}\right]-\eta\left[p_{s, t+i}-p_{t+i}\right], \quad s=1,2, \\
y_{F, j, s, t+i} & =y_{t+i}-\theta\left[p_{F, j, s, t}-p_{F, s, t+i}\right]-\rho\left[p_{F, s, t+i}-p_{s, t+i}\right]-\eta\left[p_{s, t+i}-p_{t+i}\right], \quad s=1,2, \\
y_{H, j, s, t+i}^{*} & =y_{t+i}^{*}-\theta\left[p_{H, j, s, t}^{*}-p_{H, s, t+i}^{*}\right]-\rho\left[p_{H, s, t+i}^{*}-p_{s, t+i}^{*}\right]-\eta\left[p_{s, t+i}^{*}-p_{t+i}^{*}\right], \quad s=1,2, \\
y_{F, j, s, t+i}^{*} & =y_{t+i}^{*}-\theta\left[p_{F, j, s, t}^{*}-p_{F, s, t+i}^{*}\right]-\rho\left[p_{F, s, t+i}^{*}-p_{s, t+i}^{*}\right]-\eta\left[p_{s, t+i}^{*}-p_{t+i}^{*}\right], \quad s=1,2,
\end{aligned}
$$

for all times $t+i$ for which the price set at $t$ is still in effect. 
For the output aggregations, for $s=1,2$, we have:

$$
\begin{aligned}
y_{t} & =f y_{1, t}+(1-f) y_{2, t} \\
y_{s, t} & =\omega y_{H, s, t}+(1-\omega) y_{F, s, t}, \\
y_{H, s, t} & =\int_{0}^{1} y_{H, j, s, t} d j, \\
y_{F, s, t} & =\int_{0}^{1} y_{F, j, s, t} d j, \\
y_{F, s, t}^{*} & =\int_{0}^{1} y_{F, j, s, t}^{*} d j, \\
y_{H, s, t}^{*} & =\int_{0}^{1} y_{H, j, s, t}^{*} d j .
\end{aligned}
$$

The marginal cost is given by:

$$
m c_{j, t}=w_{t}-p_{t}=\sigma c_{t}+\gamma n_{t}
$$

Loglinearizing the equation for the prices set by firms in each sector when they are called to adjust, for $s=1,2$ :

$$
\begin{gathered}
x_{H, s, t}=\left(1-\beta\left(1-\alpha_{s}\right)\right) E_{t} \sum_{j=0}^{\infty} \beta^{j}(1-\alpha)^{j}\left(p_{t+j}+m c_{t+j}\right), \\
x_{F, s, t}=\left(1-\beta\left(1-\alpha_{s}\right)\right) E_{t} \sum_{j=0}^{\infty} \beta^{j}(1-\alpha)^{j}\left(p_{t+j}+q_{t+j}+m c_{t+j}^{*}\right), \\
x_{H, s, t}^{*}=\left(1-\beta\left(1-\alpha_{s}\right)\right) E_{t} \sum_{j=0}^{\infty} \beta^{j}(1-\alpha)^{j}\left(p_{t+j}^{*}-q_{t+j}+m c_{t+j}\right), \\
x_{F, s, t}^{*}=\left(1-\beta\left(1-\alpha_{s}\right)\right) E_{t} \sum_{j=0}^{\infty} \beta^{j}(1-\alpha)^{j}\left(p_{t+j}^{*}+m c_{t+j}^{*}\right) .
\end{gathered}
$$




\section{B.2.1 Phillips curves}

Using $x_{H, s, t}-p_{H, s, t}=\frac{1-\alpha}{\alpha} \pi_{H, s, t}$ :

$$
\begin{aligned}
x_{H, s, t}= & \left(1-\beta\left(1-\alpha_{k}\right)\right) E_{t} \sum_{j=0}^{\infty} \beta^{j}(1-\alpha)^{j}\left(p_{t+j}+m c_{t+j}\right) \\
\Rightarrow \quad & \\
\frac{1-\alpha_{s}}{\alpha_{s}} \pi_{H, s, t}= & \frac{\alpha_{s}\left(1-\beta\left(1-\alpha_{s}\right)\right)}{1-\alpha_{s}}\left(p_{t}-p_{H, s, t}+m c_{t}\right)+\beta(1-\alpha) E_{t} \pi_{H, s, t+1} \\
& +\left(1-\beta\left(1-\alpha_{s}\right)\right) E_{t} \sum_{j=1}^{\infty} \beta^{j}\left(1-\alpha_{s}\right)^{j}\left(p_{t+j}-p_{H, s, t+j}+m c_{t+j}\right) \\
& +\sum_{i=2}^{\infty} \beta^{i}(1-\alpha)^{i} E_{t} \pi_{H, s, t+i} \\
\Rightarrow \quad & \frac{\alpha_{s}\left(1-\beta\left(1-\alpha_{s}\right)\right)}{1-\alpha_{s}}\left(m c_{t}-r p_{H, s, t}\right)+\beta E_{t} \pi_{H, s, t+1},
\end{aligned}
$$

where $r p_{H, s, t}=-\left(p_{t}-p_{H, s, t}\right)$.

Similarly:

$$
\begin{aligned}
\pi_{F, s, t} & =\frac{\alpha_{s}\left(1-\beta\left(1-\alpha_{s}\right)\right)}{1-\alpha_{s}}\left(m c_{t}^{*}+q_{t}-r p_{F, s, t}\right)+\beta E_{t} \pi_{F, s, t+1}, \\
x_{H, s, t}^{*} & =\frac{\alpha_{s}\left(1-\beta\left(1-\alpha_{s}\right)\right)}{1-\alpha_{s}}\left(m c_{t}-q_{t}-r p_{H, s, t}^{*}\right)+\beta E_{t} \pi_{H, s, t+1}^{*}, \\
x_{F, s, t}^{*} & =\frac{\alpha_{s}\left(1-\beta\left(1-\alpha_{s}\right)\right)}{1-\alpha_{s}}\left(m c_{t}^{*}-r p_{F, s, t}^{*}\right)+\beta E_{t} \pi_{F, t+1}^{*} .
\end{aligned}
$$

Aggregating sectoral inflation yields:

$$
\begin{aligned}
\pi_{s, t}= & \omega \pi_{H, s, t}+(1-\omega) \pi_{F, s, t} \\
= & \omega\left[\kappa_{s}\left(m c_{t}-r p_{H, s, t}\right)+\beta E_{t} \pi_{H, s, t+1}\right] \\
& +(1-\omega)\left[\kappa_{s}\left(m c_{t}^{*}+q_{t}-r p_{F, s, t}\right)+\beta E_{t} \pi_{F, s, t+1}\right]
\end{aligned}
$$

and

$$
\begin{aligned}
\pi_{s, t}^{*}= & \omega\left[\kappa_{s}\left(m c_{t}^{*}-r p_{F, s, t}^{*}\right)+\beta E_{t} \pi_{F, t+1}^{*}\right] \\
& +(1-\omega)\left[\kappa_{s}\left(m c_{t}-q_{t}-r p_{H, s, t}^{*}\right)+\beta E_{t} \pi_{H, s, t+1}^{*}\right]
\end{aligned}
$$

Assuming no home bias, $\omega=(1-\omega)$, implies:

$$
d \pi_{s, t}=\beta E_{t} d \pi_{s, t+1}-\kappa_{s} d r p_{s, t}+\kappa_{s} q_{t}
$$


Aggregating inflation across sectors:

$$
\begin{aligned}
& \pi_{t}= f \pi_{1, t}+(1-f) \pi_{2, t} \\
&= \omega f\left(\kappa_{1}+\kappa_{2}\right) m c_{t}+\omega f\left(\kappa_{1}+\kappa_{2}\right) m c_{t}^{*}+\omega f\left(\kappa_{1}+\kappa_{2}\right) q_{t} \\
&-\omega f\left\{\kappa_{1} r p_{H, 1, t}+\kappa_{2} r p_{H, 2, t}\right\}-\omega f\left\{\kappa_{1} r p_{F, 1, t}+\kappa_{2} r p_{F, 2, t}\right\}+\beta\left[E_{t} \pi_{t+1}\right] \\
& \pi_{t}^{*}= f \pi_{1, t}^{*}+(1-f) \pi_{2, t}^{*} \\
&= \omega f\left(\kappa_{1}+\kappa_{2}\right) m c_{t}+\omega f\left(\kappa_{1}+\kappa_{2}\right) m c_{t}^{*}-\omega f\left(\kappa_{1}+\kappa_{2}\right) q_{t} \\
& \quad-\omega f\left\{\kappa_{1} r p_{F, 1, t}^{*}+\kappa_{2} r p_{F, 2, t}^{*}\right\}-\omega f\left\{\left[\kappa_{1} r p_{H, 1, t}^{*}+\kappa_{2} r p_{H, 2, t}^{*}\right]\right\}
\end{aligned}
$$

Assuming equal sectoral expenditure weights, $f=(1-f)$, implies:

$$
d \pi_{t}=\beta\left[E_{t} d \pi_{t+1}\right]+f\left(\kappa_{1}+\kappa_{2}\right) q_{t}-f\left\{\kappa_{1} d r p_{1, t}+\kappa_{2} d r p_{2, t}\right\},
$$

where:

$$
\begin{aligned}
r p_{s, t} & =\omega r p_{H, s, t}+(1-\omega) r p_{F, s, t}=\omega\left(p_{H, s, t}-p_{t}\right)+(1-\omega)\left(p_{F, s, t}-p_{t}\right)=p_{s, t}-p_{t} \\
r p_{s, t}^{*} & =\omega r p_{F, s, t}^{*}+(1-\omega) r p_{H, s, t}^{*}=p_{s, t}^{*}-p_{t}^{*} \\
d r p_{s, t} & =r p_{s, t}-r p_{s, t}^{*}
\end{aligned}
$$

Rewriting $d r p_{2, t}$ :

$$
\begin{aligned}
p_{t} & =f p_{1, t}+(1-f) p_{2, t} \Rightarrow p_{2, t}=\frac{p_{t}-f p_{1, t}}{1-f} \\
p_{2, t}-p_{t} & =\frac{p_{t}-f p_{1, t}}{1-f}-p_{t}=-\frac{f}{1-f} d r p_{1, t}=-d r p_{1, t}
\end{aligned}
$$

Therefore,

$$
d \pi_{t}=\beta E_{t} d \pi_{t+1}+f\left(\kappa_{1}+\kappa_{2}\right) q_{t}+f\left(\kappa_{2}-\kappa_{1}\right) d r p_{1, t} .
$$

Note that the previous equation nests the standard NKPC without heterogeneity, $\alpha_{1}=$ $\alpha_{2} \Rightarrow \kappa_{1}=\kappa_{2}=\kappa:$

$$
d \pi_{t}=\beta E_{t} d \pi_{t+1}+\kappa q_{t}
$$

The heterogeneity in frequency of price adjustment, therefore, affects inflation dynamics through the term $f\left(\kappa_{2}-\kappa_{1}\right) d r p_{1, t}$. The effect is amplified when heterogeneity is large and countries' relative sectoral prices are large. 
Finally, note that:

$$
d r p_{1, t}=d r p_{1, t-1}+d \pi_{1, t}-d \pi_{t}
$$

Therefore, the model in deviations between Home and Foreign, where any variable labeled as $d x_{t}$ corresponds to $d x_{t}=x_{t}-x_{t}^{*}$, is summarized by:

$$
\begin{aligned}
d \pi_{t} & =\beta E_{t} d \pi_{t+1}+f\left(\kappa_{1}+\kappa_{2}\right) q_{t}+f\left(\kappa_{2}-\kappa_{1}\right) d r p_{1, t} \\
d i_{t} & =E_{t} q_{t+1}-q_{t}+E_{t} d \pi_{t+1} \\
d \pi_{1, t} & =\beta E_{t} d \pi_{1, t+1}+\kappa_{1} q_{t}-\kappa_{1} d r p_{1, t} \\
d r p_{1, t} & =d r p_{1, t-1}+d \pi_{1, t}-d \pi_{t} \\
d i_{t} & =\rho_{i} d i_{t-1}+\left(1-\rho_{i}\right) \phi_{\pi} d \pi_{t}+v_{t}, \\
v_{t} & =\rho_{v} v_{t-1}+\varepsilon_{t}^{v},
\end{aligned}
$$

where we assume that the exogenous component of the interest rate follows an $\mathrm{AR}(1)$ process and $\rho_{v} \in[0,1)$.

Guess the solution will take the form:

$$
\begin{aligned}
d \pi_{t} & =\varphi_{\pi} v_{t}+\gamma_{\pi} d i_{t-1}+\theta_{\pi} d r p_{1, t-1} \\
q_{t} & =\varphi_{q} v_{t}+\gamma_{q} d i_{t-1}+\theta_{q} d r p_{1, t-1} \\
d r p_{1, t} & =\varphi_{p} v_{t}+\gamma_{p} d i_{t-1}+\theta_{p} d r p_{1, t-1}
\end{aligned}
$$

From these equations:

$$
\begin{aligned}
d i_{t} & =\rho_{i} d i_{t-1}+\left(1-\rho_{i}\right) \phi_{\pi} d \pi_{t}+v_{t} \\
& =\rho_{i} d i_{t-1}+\left(1-\rho_{i}\right) \phi_{\pi}\left[\varphi_{\pi} v_{t}+\gamma_{\pi} d i_{t-1}+\theta_{\pi} d r p_{t-1}\right]+v_{t} \\
& =\left[1+\left(1-\rho_{i}\right) \phi_{\pi} \varphi_{\pi}\right] v_{t}+\left[\rho_{i}+\left(1-\rho_{i}\right) \phi_{\pi} \gamma_{\pi}\right] d i_{t-1}+\left(1-\rho_{i}\right) \phi_{\pi} \theta_{\pi} d r p_{t-1} \\
d i_{t} & =\varphi_{i} v_{t}+\gamma_{i} d i_{t-1}+\theta_{i} d r p_{t-1}
\end{aligned}
$$


Hence, we have a system:

$$
\begin{aligned}
d \pi_{t} & =\varphi_{\pi} v_{t}+\gamma_{\pi} d i_{t-1}+\theta_{\pi} d r p_{1, t-1} \\
q_{t} & =\varphi_{q} v_{t}+\gamma_{q} d i_{t-1}+\theta_{q} d r p_{1, t-1} \\
d r p_{1, t} & =\varphi_{p} v_{t}+\gamma_{p} d i_{t-1}+\theta_{p} d r p_{1, t-1} \\
d i_{t} & =\varphi_{i} v_{t}+\gamma_{i} d i_{t-1}+\theta_{i} d r p_{t-1}
\end{aligned}
$$

Departing from equation (15):

$$
\begin{aligned}
q_{t}= & -d i_{t}+E_{t} q_{t+1}+E_{t} d \pi_{t+1} \\
= & \left(-\varphi_{i}+\gamma_{q} \varphi_{i}+\varphi_{q} \rho_{v}+\varphi_{\pi} \rho_{v}+\theta_{q} \varphi_{p}+\gamma_{\pi} \varphi_{i}+\theta_{\pi} \varphi_{p}\right) v_{t} \\
& +\left(-\gamma_{i}+\gamma_{q} \gamma_{i}+\gamma_{\pi} \gamma_{i}+\theta_{\pi} \gamma_{p}+\theta_{q} \gamma_{p}\right) d i_{t-1} \\
& +\left(-\theta_{i}+\gamma_{q} \theta_{i}+\theta_{q} \theta_{p}+\gamma_{\pi} \theta_{i}+\theta_{\pi} \theta_{p}\right) d r p_{1, t-1}
\end{aligned}
$$

Departing from equation (16):

$$
\begin{aligned}
d \pi_{t}= & \beta E_{t} d \pi_{t+1}+f\left(\kappa_{1}+\kappa_{2}\right) q_{t}+f\left(\kappa_{2}-\kappa_{1}\right) d r p_{1, t} \\
= & \left(\beta \varphi_{\pi} \rho_{v}+\beta \gamma_{\pi} \varphi_{i}+\beta \theta_{\pi} \varphi_{p}+f\left(\kappa_{1}+\kappa_{2}\right) \varphi_{q}+f\left(\kappa_{2}-\kappa_{1}\right) \varphi_{p}\right) v_{t} \\
& +\left(\beta \gamma_{\pi} \gamma_{i}+\beta \theta_{\pi} \gamma_{p}+f\left(\kappa_{1}+\kappa_{2}\right) \gamma_{q}+f\left(\kappa_{2}-\kappa_{1}\right) \gamma_{p}\right) d i_{t-1} \\
& +\left(\beta \gamma_{\pi} \theta_{i}+\beta \theta_{\pi} \theta_{p}+f\left(\kappa_{1}+\kappa_{2}\right) \theta_{q}+f\left(\kappa_{2}-\kappa_{1}\right) \theta_{p}\right) d r p_{1, t-1}
\end{aligned}
$$

Departing from equation (17), and using $d r p_{1, t}-d r p_{1, t-1}+d \pi_{t}=+d \pi_{1, t}$ (from equation (18)):

$$
\begin{aligned}
d \pi_{1, t}= & \beta E_{t} d \pi_{1, t+1}+\kappa_{1} q_{t}-\kappa_{1} d r p_{1, t} \\
d r p_{1, t}-d r p_{1, t-1}+d \pi_{t}= & \beta E_{t}\left[d r p_{1, t+1}-d r p_{1, t}+d \pi_{t+1}\right]+\kappa_{1} q_{t}-\kappa_{1} d r p_{1, t} \\
\left(1+\kappa_{1}+\beta-\beta \theta_{p}-\beta \theta_{\pi}\right) d r p_{1, t}= & \left(\left(\beta \varphi_{p}+\beta \varphi_{\pi}\right) \rho_{v}+\left(\beta \gamma_{p}+\beta \gamma_{\pi}\right) \varphi_{i}-\varphi_{\pi}+\kappa_{1} \varphi_{q}\right) v_{t} \\
& +\left(\left(\beta \gamma_{p}+\beta \gamma_{\pi}\right) \gamma_{i}-\gamma_{\pi}+\kappa_{1} \gamma_{q}\right) d i_{t-1} \\
& +\left(\left(\beta \gamma_{p}+\beta \gamma_{\pi}\right) \theta_{i}-\theta_{\pi}+\kappa_{1} \theta_{q}+1\right) d r p_{1, t-1} .
\end{aligned}
$$


These yield a system of 12 variables and 12 equations:

$$
\begin{aligned}
& \varphi_{i}=\left(1+\left(1-\rho_{i}\right) \phi_{\pi} \varphi_{\pi}\right) \\
& \gamma_{i}=\left(\rho_{i}+\left(1-\rho_{i}\right) \phi_{\pi} \gamma_{\pi}\right) \\
& \theta_{i}=\left(1-\rho_{i}\right) \phi_{\pi} \theta_{\pi} \\
& \varphi_{q}=\left(-\varphi_{i}+\gamma_{q} \varphi_{i}+\varphi_{q} \rho_{v}+\varphi_{\pi} \rho_{v}+\theta_{q} \varphi_{p}+\gamma_{\pi} \varphi_{i}+\theta_{\pi} \varphi_{p}\right) \\
& \gamma_{q}=\left(-\gamma_{i}+\gamma_{q} \gamma_{i}+\gamma_{\pi} \gamma_{i}+\theta_{\pi} \gamma_{p}+\theta_{q} \gamma_{p}\right) \\
& \theta_{q}=\left(-\theta_{i}+\gamma_{q} \theta_{i}+\theta_{q} \theta_{p}+\gamma_{\pi} \theta_{i}+\theta_{\pi} \theta_{p}\right) \\
& \varphi_{\pi}=\left(\beta \varphi_{\pi} \rho_{v}+\beta \gamma_{\pi} \varphi_{i}+\beta \theta_{\pi} \varphi_{p}+f\left(\kappa_{1}+\kappa_{2}\right) \varphi_{q}+f\left(\kappa_{2}-\kappa_{1}\right) \varphi_{p}\right) \\
& \gamma_{\pi}=\left(\beta \gamma_{\pi} \gamma_{i}+\beta \theta_{\pi} \gamma_{p}+f\left(\kappa_{1}+\kappa_{2}\right) \gamma_{q}+f\left(\kappa_{2}-\kappa_{1}\right) \gamma_{p}\right) \\
& \theta_{\pi}=\left(\beta \gamma_{\pi} \theta_{i}+\beta \theta_{\pi} \theta_{p}+f\left(\kappa_{1}+\kappa_{2}\right) \theta_{q}+f\left(\kappa_{2}-\kappa_{1}\right) \theta_{p}\right) \\
& \varphi_{p}=\frac{\left(\left(\beta \varphi_{p}+\beta \varphi_{\pi}\right) \rho_{v}+\left(\beta \gamma_{p}+\beta \gamma_{\pi}\right) \varphi_{i}-\varphi_{\pi}+\kappa_{1} \varphi_{q}\right)}{\left(1+\kappa_{1}+\beta-\beta \theta_{p}-\beta \theta_{\pi}\right)} \\
& \gamma_{p}=\frac{\left(\left(\beta \gamma_{p}+\beta \gamma_{\pi}\right) \gamma_{i}-\gamma_{\pi}+\kappa_{1} \gamma_{q}\right)}{\left(1+\kappa_{1}+\beta-\beta \theta_{p}-\beta \theta_{\pi}\right)} \\
& \theta_{p}=\frac{\left(\left(\beta \gamma_{p}+\beta \gamma_{\pi}\right) \theta_{i}-\theta_{\pi}+\kappa_{1} \theta_{q}+1\right)}{\left(1+\kappa_{1}+\beta-\beta \theta_{p}-\beta \theta_{\pi}\right)}
\end{aligned}
$$

\section{Additional results}

\section{C.1 Comparative statistics varying persistence}

Figure A3 reports comparative statics results when varying the persistence of policy shocks $\left(\rho_{v}\right)$ in the calibrated models. As in Figure 1, dashed lines indicate one-sector economies, whereas solid lines correspond to the three-sector models. The top charts consider the case without policy inertia $\left(\rho_{i}=0\right)$, while the bottom ones assume instead $\rho_{i}=0.975$. The main takeaway from a comparison between the top and the bottom charts is that a multisector model that includes persistent shocks as the only source of exogenous persistence can generate humpshaped responses of the RER. Once policy inertia is introduced, all measures of persistence 
drop substantially and the impulse response functions fail to exhibit a hump-shaped response to monetary shocks. ${ }^{19}$

\section{C.2 Results with technology shocks}

We rely on the same simplifying assumptions as before but assume a technology shock to the production function of intermediate firms such that:

$$
\begin{aligned}
\omega y_{H, j, t}+(1-\omega) y_{H, j, t}^{*} & =a_{t}+n_{j, t}^{d} \\
\omega y_{H, t}+(1-\omega) y_{H, t}^{*} & =a_{t}+n_{t}^{d},
\end{aligned}
$$

where $a_{t}=\rho_{a} a_{t-1}+\varepsilon_{t}^{a}$ and $\rho_{a} \in[0,1)$.

Under these assumptions, the pricing equation for the intermediate firms are such that:

$$
\begin{gathered}
x_{H, t}=\left(1-\beta\left(1-\alpha_{k}\right)\right) E_{t} \sum_{j=0}^{\infty} \beta^{j}(1-\alpha)^{j}\left(p_{t+j}+m c_{t+j}-a_{t}\right), \\
x_{F, t}=\left(1-\beta\left(1-\alpha_{k}\right)\right) E_{t} \sum_{j=0}^{\infty} \beta^{j}(1-\alpha)^{j}\left(p_{t+j}+q_{t+j}+m c_{t+j}^{*}-a_{t}^{*}\right), \\
x_{H, t}^{*}=(1-\beta(1-\alpha)) E_{t} \sum_{j=0}^{\infty} \beta^{j}(1-\alpha)^{j}\left(p_{t+j}^{*}-q_{t+j}+m c_{t+j}-a_{t}\right), \\
x_{F, t}^{*}=(1-\beta(1-\alpha)) E_{t} \sum_{j=0}^{\infty} \beta^{j}(1-\alpha)^{j}\left(p_{t+j}^{*}+m c_{t+j}^{*}-a_{t}^{*}\right) .
\end{gathered}
$$

Lastly, the market-clearing condition becomes $y_{t}=c_{t}=a_{t}+n_{t}$.

The simple model can be written in deviations between Home and Foreign variables:

$$
\begin{aligned}
d \pi_{t} & =\delta q_{t}-\left(a_{t}-a_{t}^{*}\right)+\beta E_{t}\left(\pi_{t+1}-\pi_{t+1}^{*}\right), \\
d i_{t} & =E_{t} q_{t+1}-q_{t}+E_{t}\left(\pi_{t+1}-\pi_{t+1}^{*}\right) .
\end{aligned}
$$

\footnotetext{
${ }^{19}$ The different values for $\rho_{i}$ and $\rho_{v}$ used to construct each panel in Figures 1 and A3 can imply substantially different levels of persistence in nominal interest rates. To complement the analysis, we redo our analysis adjusting the values of $\rho_{i}$ and $\rho_{v}$ to obtain the same level of nominal interest rate persistence as in the baseline specification $\left(\rho_{i}=0, \rho_{v}=0.975\right)$. More specifically, for each $\rho_{i}$ in $[0,1)$, we set $\rho_{v}$ such that nominal interest rate persistence, as measured by the cumulative impulse response $(\mathcal{C} \mathcal{I} \mathcal{R})$, equals that in the baseline specifications of the multisector and one-sector economies. Results, which are available upon request, reinforce the finding that as the degree of policy inertia increases, RER persistence declines.
} 
And assuming the same interest rate rule for both countries, we have:

$$
d i_{t}=\phi_{i} d i_{t-1}+\left(1-\phi_{i}\right) \phi_{\pi} d \pi_{t}+v_{t}
$$

The solution to the model will take the form:

$$
\begin{aligned}
q_{t} & =\varphi_{q v} v_{t}+\gamma_{q} d i_{t-1}+\lambda_{q a} a_{t} \\
d \pi_{t} & =\varphi_{\pi v} v_{t}+\gamma_{\pi} d i_{t-1}+\lambda_{\pi a} a_{t}
\end{aligned}
$$

where $\varphi_{q v}, \gamma_{q}, \lambda_{q a}, \varphi_{\pi v}, \gamma_{\pi}$, and $\lambda_{\pi a}$ are negative coefficients such that:

$$
\begin{aligned}
\varphi_{q v} & =\left[-\left(1-\phi_{i}\right) \phi_{\pi} \varphi_{\pi v}+\varphi_{q v} \rho_{v}+\gamma_{q}\left(1-\phi_{i}\right) \phi_{\pi} \varphi_{\pi v}+\gamma_{q}+\varphi_{\pi v} \rho_{v}+\gamma_{\pi}\left(1-\phi_{i}\right) \phi_{\pi} \varphi_{\pi v}+\gamma_{\pi}-1\right] \\
\varphi_{\pi v} & =\left[\beta \varphi_{\pi v} \rho_{v}+\beta \gamma_{\pi}\left(1-\phi_{i}\right) \phi_{\pi} \varphi_{\pi v}+\beta \gamma_{\pi}+\delta \varphi_{q v}\right], \\
\gamma_{q} & =\left[-\left(1-\phi_{i}\right) \phi_{\pi} \gamma_{\pi}+\gamma_{q} \phi_{i}+\gamma_{q}\left(1-\phi_{i}\right) \phi_{\pi} \gamma_{\pi}+\gamma_{\pi} \phi_{i}+\gamma_{\pi}\left(1-\phi_{i}\right) \phi_{\pi} \gamma_{\pi}-\phi_{i}\right], \\
\gamma_{\pi} & =\left[+\beta \gamma_{\pi} \phi_{i}+\beta \gamma_{\pi}\left(1-\phi_{i}\right) \phi_{\pi} \gamma_{\pi}+\delta \gamma_{q}\right] \\
\lambda_{q a} & =\left[-\left(1-\phi_{i}\right) \phi_{\pi} \lambda_{\pi a}+\lambda_{q a} \rho_{a}+\gamma_{q}\left(1-\phi_{i}\right) \phi_{\pi} \lambda_{\pi a}+\gamma_{\pi}\left(1-\phi_{i}\right) \phi_{\pi} \lambda_{\pi a}+\lambda_{\pi a} \rho_{a}\right], \\
\lambda_{\pi a} & =\left[+\beta \lambda_{\pi a} \rho_{a}+\beta \gamma_{\pi}\left(1-\phi_{i}\right) \phi_{\pi} \lambda_{\pi a}+\delta \lambda_{q a}-1\right] .
\end{aligned}
$$

Following similar steps as before, persistence as measured by the $\mathcal{C} \mathcal{I} \mathcal{R}$ in response to a technology shock is given by:

$$
C I R=\frac{1}{1-\rho_{a}}+\underbrace{\frac{\gamma_{q}}{\lambda_{q a}}}_{>0} \frac{1}{\left(1-\rho_{i}\right)\left(1-\phi_{\pi} \gamma_{\pi}\right)} .
$$

Therefore, in the simplified one-sector economy, policy inertia unequivocally increases persistence in response to technology shocks.

Figure A4 considers the role of policy inertia in out calibrated multisector and one-sector models. More specifically, the figure reports the cumulative impulse responses of the real exchange rate in response to a technology shock for ranging values (from 0 to 0.95) of policy inertia $\rho_{i}$ and technology shock persistence $\rho_{a}$. The left-hand-side panel shows results for the multisector economy, while the right-hand-side panel shows results for the one-sector one. Both panels show that the persistence of the real exchange rate in response to a technology shock as measured by the $\mathcal{C} \mathcal{I} \mathcal{R}$ increases with policy inertia. 
Figure A2: RER persistence in response to monetary shocks for varying degrees of policy inertia

\section{Varying policy inertia $\left(\rho_{i}\right)$ when monetary shocks are:}

$$
\text { (a) i.i.d. } \quad\left(\rho_{v}=0\right)
$$

Cumulative impulse response and half-live

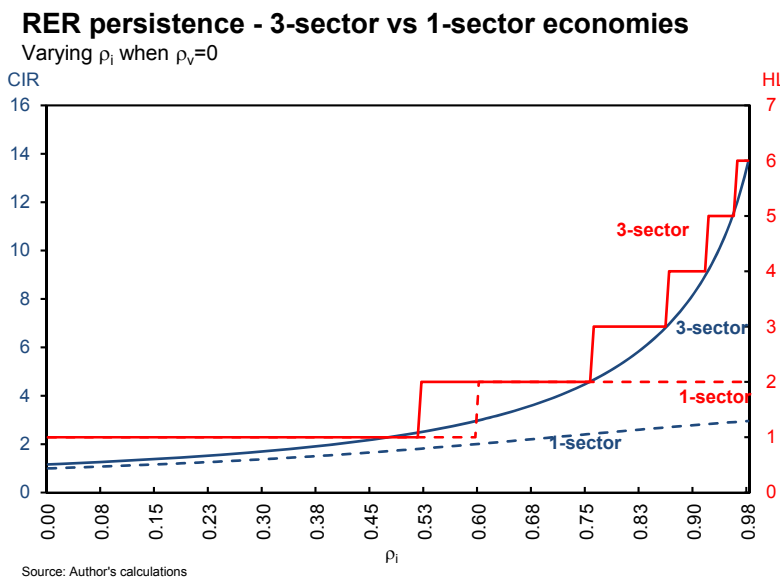

Up-life and first autocorrelation

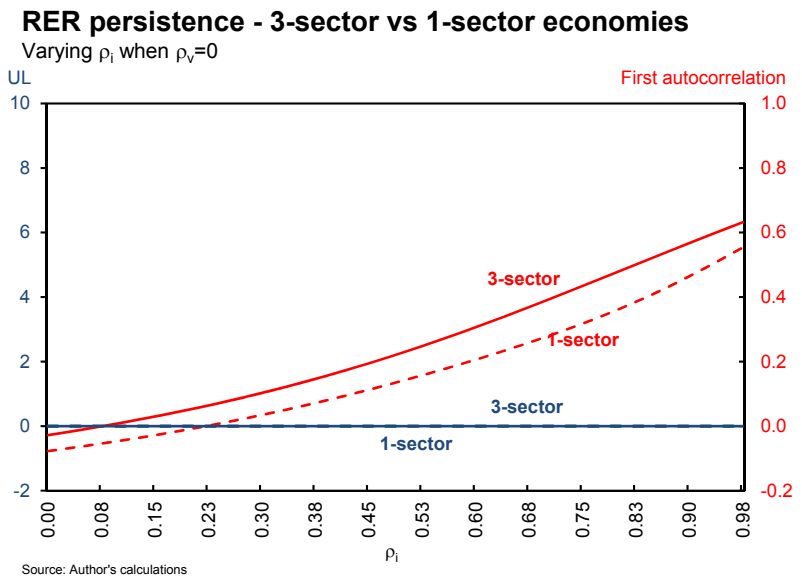

(b) persistent $\left(\rho_{v}>0\right)$

Cumulative impulse response and half-live

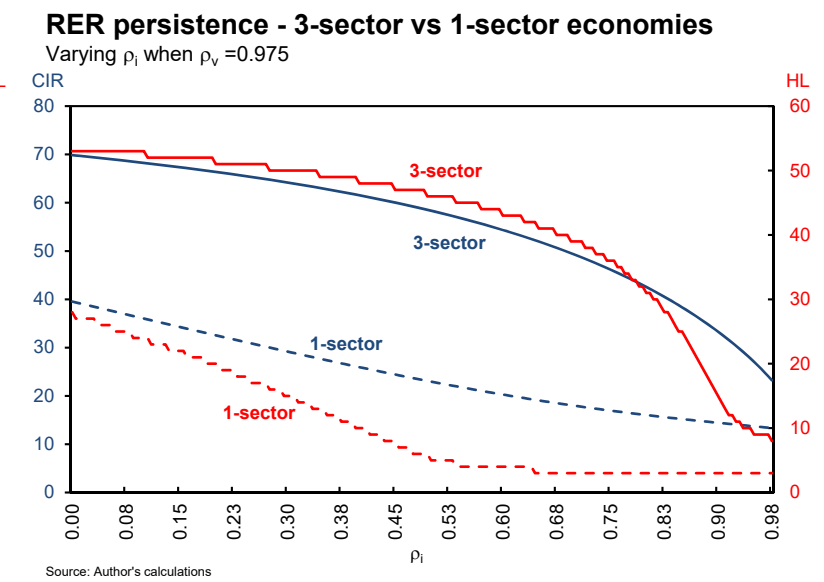

Up-life and first autocorrelation

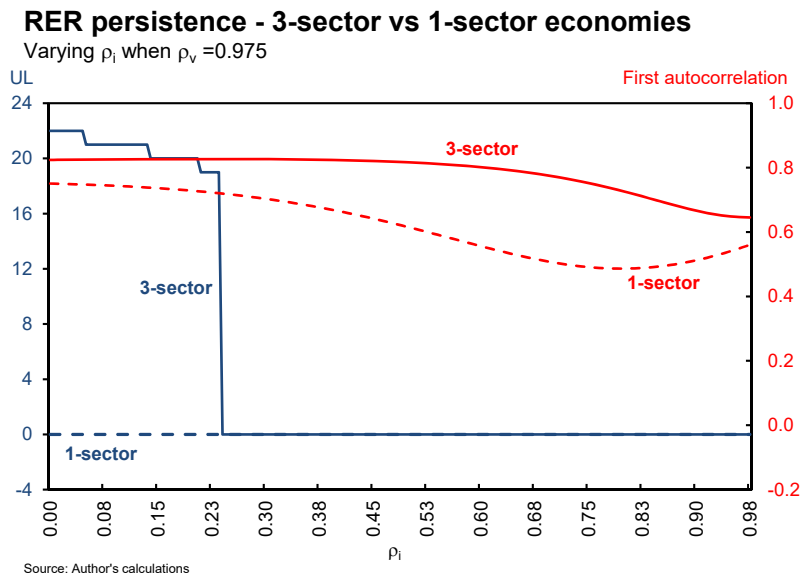


Figure A3: RER persistence in response to monetary shocks for varying shock persistence

\section{Varying shock persistence $\left(\rho_{v}\right)$ when rule features:}

\section{(a) no policy inertia}

Cumulative impulse response and half-life

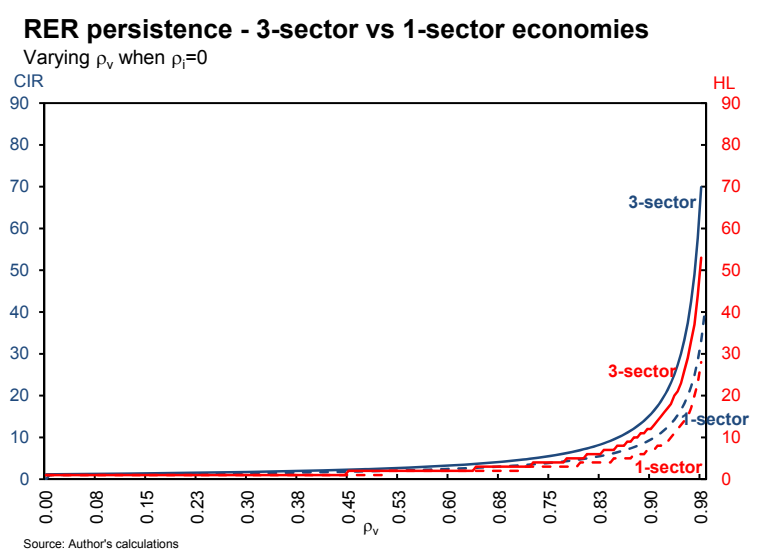

Up-life and first autocorrelation

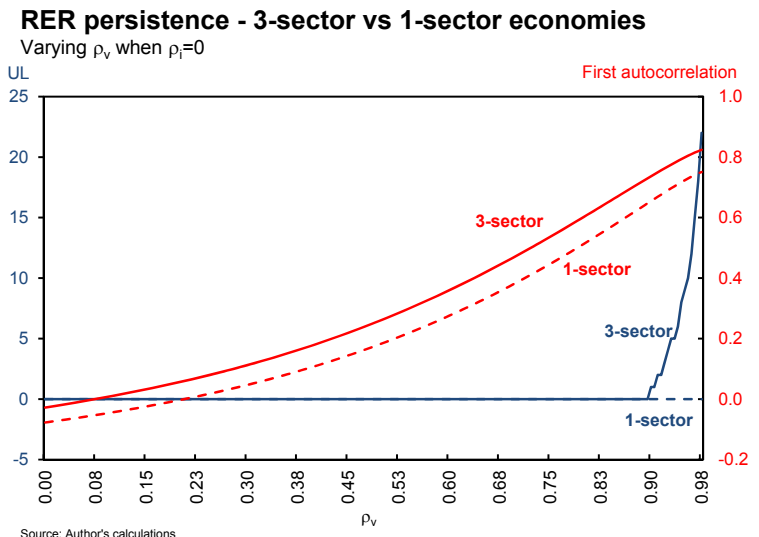

(b) policy inertia

Cumulative impulse response and half-life

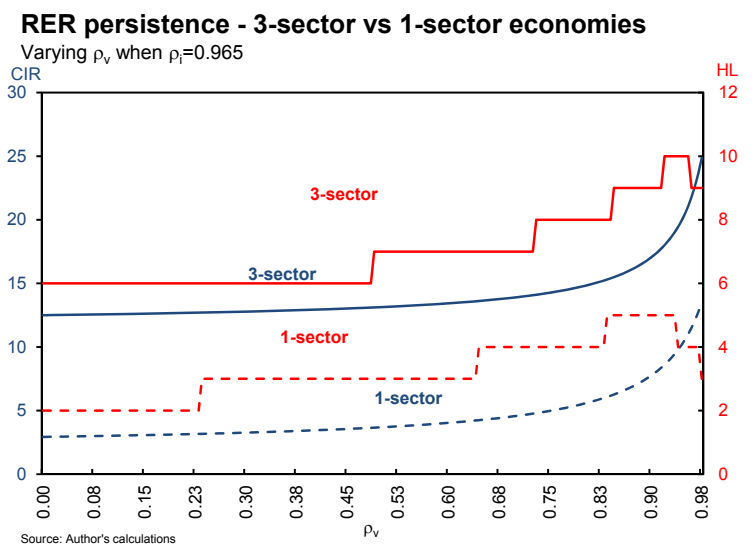

Up-life and first autocorrelation

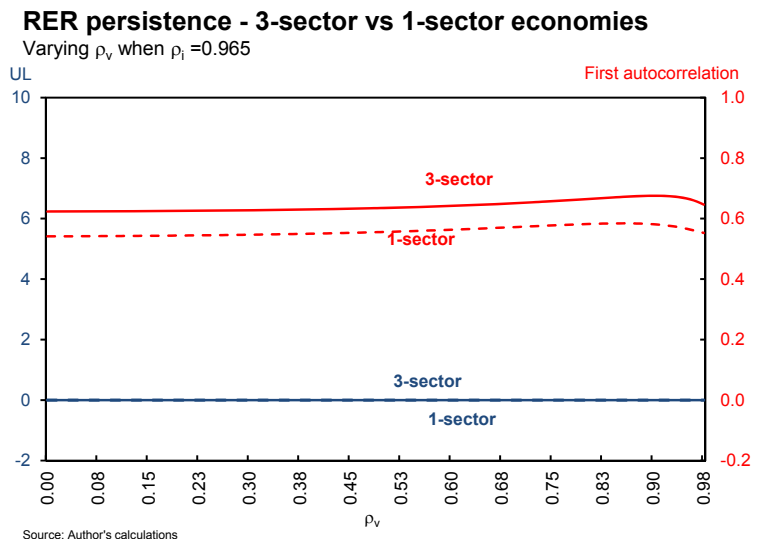


Figure A4: RER persistence in response to a technology shock for varying shock persistence and policy inertia

\section{Multisector economy}

Real exchange rate cumulative impulse response Varying $\rho_{i}$ and $\rho_{a}$

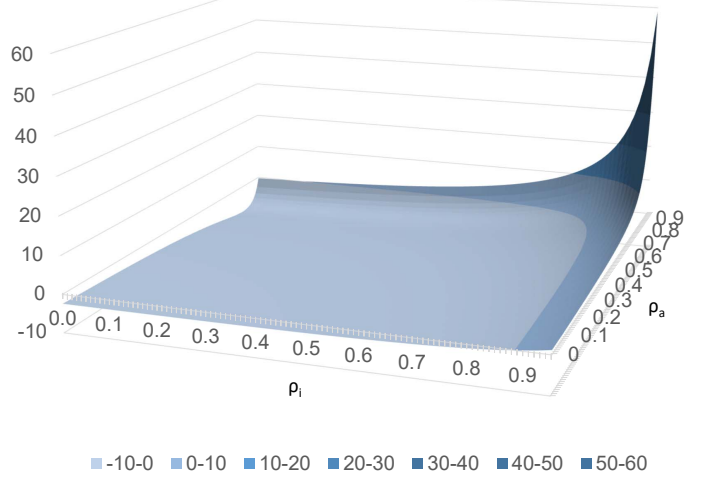

\section{One-sector economy}

Real exchange rate cumulative impulse response Varying $\rho_{\mathrm{i}}$ and $\rho_{\mathrm{a}}$

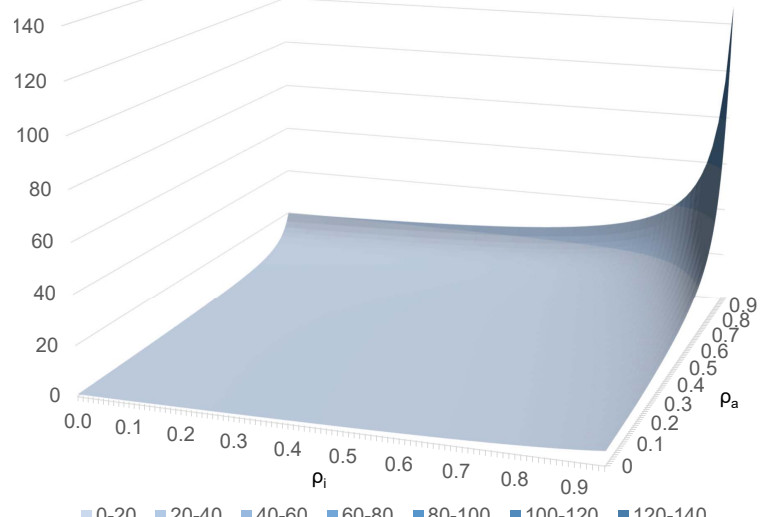

